\title{
MicroRNA-410 acts as oncogene in NSCLC through downregulating SLC34A2 via activating Wnt/ $\beta$-catenin pathway
}

\author{
Xuechao Zhang ${ }^{1, *}$, Xixian Ke ${ }^{1, *}$, Qiang Pu², Yue Yuan ${ }^{1}$, Weihan Yang ${ }^{1}$, Xinmei Luo ${ }^{1}$, \\ Qianqian Jiang ${ }^{1}$, Xueting Hu${ }^{1}$, Yi Gong ${ }^{1}$, Kui Tang ${ }^{1}$, Xiaolan Su${ }^{1}$, LunXu Liu ${ }^{2}$, Wen \\ Zhu ${ }^{1}$ and Yuquan Wei ${ }^{1}$ \\ ${ }^{1}$ State Key Laboratory of Biotherapy/Collaborative Innovation Center of Biotherapy, West China Hospital, Sichuan University, \\ Chengdu, Sichuan Province, People's Republic of China \\ 2 Department of Thoracic Surgery, West China Hospital, Sichuan University, Chengdu, Sichuan Province, People's Republic \\ of China \\ * These authors have contributed equally to this work \\ Correspondence to: Wen Zhu, email: zhuwen@scu.edu.cn
}

Lunxu Liu, email: Iunxu_liu@aliyun.com

Keywords: miR-410, SLC34A2, NSCLC, tumorigenesis and development

Received: July 30, $2015 \quad$ Accepted: December 31, $2015 \quad$ Published: February 20, 2016

\section{ABSTRACT}

SLC34A2 had been reported to be down-regulated in human NSCLC cells and patient tissues, and played a significant role in lung cancer. However, the mechanism of its unusual expression in NSCLC has not been fully elucidated. In present study, we identified SLC34A2 was a direct target of miR-410 and could be inhibited by miR-410 transcriptionally and post-transcriptionally. MiR-410 promoted the growth, invasion and migration of NSCLC cells in vitro. An orthotopic xenograft nude mouse model further affirmed that miR-410 promoted NSCLC cell growth and metastasis in vivo. Moreover, restoring SLC34A2 expression effectively reversed the miR-410mediated promotion of cell growth, invasion and migration in NSCLC cells. In addition, miR-410 ${ }^{\text {high }} /$ SLC34A2 ${ }^{\text {low }}$ expression signature frequently existed in NSCLC cells and tumor tissues. MiR-410 significantly increased the expression of $D V L 2$ and $\beta$-catenin protein while decreased that of Gsk3 $\beta$ protein of Wnt/ $\beta$-catenin signaling pathway, while SLC34A2 partly blocked the effects of miR-410 on those protein expressions. Hence, our data for the first time delineated that unusual expression of SLC34A2 was modulated by miR-410, and miR-410 might positively contribute to the tumorigenesis and development of NSCLC by down-regulating SLC34A2 and activating Wnt/ $\beta$-catenin signaling pathway. MiR-410 might be a new potential therapeutic target for NSCLC.

\section{INTRODUCTION}

Lung cancer remains the world's most significant reason of cancer death and the mortality rate is still increasing [1]. Therefore, it is extremely important to elaborate the molecular mechanism of lung cancer pathogenesis and development. SLC34A2 encoding $\mathrm{NaPi} 2 \mathrm{~b}$ plays an important role in the maintenance of the overall phosphate homeostasis which is essential for proper cellular functions such as DNA synthesis, cell signaling, bone formation etc. [2,3]. SLC34A2 is a tissuespecific transporter that is highly expressed in the lung [4-8]. In human lung, SLC34A2 expresses only in Type II alveolar epithelium cells (AT-II) and is required for the synthesis of AT-II pulmonary surfactant [9-10]. ATII cells are potential stem cells of the alveolar epithelium [11]. Increasing studies reported that AT-II cells might be transformed into cancer stem cells under exogenous or endogenous factors and induced carcinogenesis and development of NSCLC finally [11-14]. These indicated that SLC34A2 might function physiologically in AT-II and its mutations or abnormal expression was bound to affect the normal function of AT-II which was related to lung tumorigenesis. Moreover, recent studies reported that SLC34A2 played a critical role in lung cancer. Kopantzev et al. revealed expression of $S L C 34 A 2$ increased during the development of fetal lung and early embryonic development, but decreased in non-small cell lung 
carcinomas tissues compared with surrounding normal lung tissues [15]. Also, our lab previously reported that SLC34A2 was down-regulated in human NSCLC tumor tissues and cells, and might act as tumor suppressor by inhibiting the growth, invasion and migration of lung cancer cells through the PI3K-Akt-mTOR and RasRaf-MEK-ERK signaling pathway $[16,17]$. However, the mechanism of unusual expression of SLC34A2 in NSCLC has not been fully elucidated. Therefore, it is of great significance to reveal the molecular mechanism of abnormal expression of SLC34A2 for understanding the pathogenesis of NSCLC.

MicroRNAs (miRNAs), a family of small noncoding single-stranded RNAs, have been shown to play important roles in cancer cells and are tightly associated with the abnormal expression of tumor-relevant genes recently [18]. MiRNA leads to transcriptional silencing of gene expression through complementary pairing in 3' UTR of its target mRNA. Recent studies acknowledged that more than 200 miRNAs regulating tumor-related genes expression were closely related to tumor development [19]. As one of the most deadly cancers, lung cancer was regulated by many miRNAs [20]. Dozens of miRNAs, such as miR-21, miR-17-92, miR-143/145, miR-34, miR200 , etc. played essential roles in lung tumorigenesis by regulating critical oncogene or tumor suppressor [21-25]. In present study, we aimed to identify a specific miRNA targeting SLC34A2 for unclosing the mechanism of aberrant expression of $S L C 34 A 2$, then further explored its function to the pathogenesis and development of NSCLC. We firstly demonstrated that $S L C 34 A 2$ was a direct target of miR-410 and inhibited by miR-410 transcriptionally and post-transcriptionally, and overexpression of miR410 significantly promoted cell growth, invasion and metastasis by down-regulating SLC34A2 via activating $\mathrm{Wnt} / \beta$ - catenin pathway. Hence, our study identified a new miRNA and signaling pathway for understanding the pathogenesis and provided promising therapeutic target for NSCLC.

\section{RESULTS}

\section{SLC34A2 was identified as a direct target of miR- 410}

Two algorithms (TargetScan, miRanda) were used to predict miRNAs targeting SLC34A2. In light of individual computer-aided algorithms usually bringing about quantities of false positives, we applied a combination of two approaches to provide a more accurate assessment of the targeting miRNA. 22 miRNAs were preliminarily filtered (data not shown) and then four of them (miR410, miR-506, miR-491, miR-384) were selected because of their lower free binding energy which meant more possibility that miRNA might bind to its target gene (Figure 1A). Next, we checked the expression of these four miRNAs by qRT-PCR in NSCLC cell line A549 in which SLC34A2 was down-regulated compared with the normal cell line HBE. The expression of miR-410 was significantly up-regulated $(p<0.05)$, miR-491 displayed no expression change, miR-384 and miR-506 were both down-regulated respectively $(p<0.05)$ in A549 cells (Figure 1B). Since miR-410 was highly expressed in A549 cells, we further detected its expression in other NSCLC cell lines H1299 and 95D in which SLC34A2 was also down-regulated compared with the normal cell line HBE. MiR-410 were significantly up-regualted in both cell lines compared with HBE $(p<0.05)$ (Figure 1C). Moreover, we found that miR-410 was significantly up-regulated and SLC34A2 was significantly down-regulated in 9 of 12 NSCLC tumor tissues compared with adjacent nontumorous tissues simultaneously by qRT-PCR (Figure 1D). These results indicated that overexpression of miR-410 might be associated with down-regulation of SLC34A2.

To further verify $S L C 34 A 2$ was a direct target of miR-410, 3'-UTR luciferase reporter plasmids containing the wild-type or mutant miR-410-binding sequences of SLC34A2 were constructed and co-transfected with miR-410 mimics/NC into HEK-293 cells. The relative luciferase activity of the reporter containing wild-type Pmir-SLC34A2 3'UTR-F was significantly reduced when miR-410 mimics were co-transfected. In contrast, the luciferase activity of the reporter containing the mutant Pmir-SLC34A2 3'UTR-R was not affected by co-transfecting with miR-410 mimics, indicating that miR-410 might inhibit gene expression through miR-410binding sequences at the 3'-UTR of SLC34A2 (Figure 1E) $(p<0.05)$.We further analyzed the effects of miR-410 on SLC34A2 expression in NSCLC cells. QRT-PCR and Western blotting were performed to check the effects of overexpression or inhibition of miR-410 on mRNA and protein expression levels of SLC34A2 in A549 and 95D cell lines. SLC34A2 mRNA was up-regulated or downregulated when transfected with miR-410 inhibitors or miR-410 mimics into both A549 and 95D cell lines both A549 and 95D cell lines (Figure 1F) $(p<0.05)$. Similarly, SLC34A2 protein level was up-regulated or downregulated when transfected with miR-410 inhibitors or miR-410 mimics into both A549 and 95D cell lines (Figure $1 \mathrm{G})(p<0.05)$. These findings further confirmed that miR410 could inhibit SLC34A2 expression transcriptionally and post-transcriptionally.

\section{MiR-410 promoted proliferation, invasion and migration but inhibited apoptosis in NSCLC}

Next, the in vitro effects of miR-410 abnormal expression on malignant phenotypes of NSCLC cells were investigated. The expression of miR-410 was significantly 
A

\begin{tabular}{|c|c|}
\hline $\begin{array}{l}\text { Position } 1282-1288 \text { of SLC34A2 3' UTR } \\
\text { hsa-miR-506 }\end{array}$ & $\begin{array}{l}\text { 5' ... CUAGAUGCCUUCUCUGUGCCUUC } \\
\text { 3, } \\
\text { AGAUGAGUCUUCCCACGGAAU }\end{array}$ \\
\hline $\begin{array}{l}\text { Position 1565-1572 of SLC34A2 3' UTR } \\
\text { hsa-miR-410 }\end{array}$ & 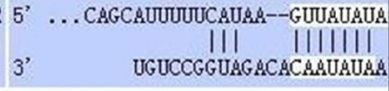 \\
\hline $\begin{array}{l}\text { Position } 1375-1382 \text { of SLC34A2 } 3 \text { ' UTR } \\
\text { hsa-miR-384 }\end{array}$ & 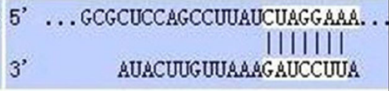 \\
\hline $\begin{array}{l}\text { Position } 570-577 \text { of SLC34A2 } 3 \text { UTR } 5^{\prime} \\
\text { hsa-miR-491-5p }\end{array}$ & $\begin{array}{l}\text {... CCCACUUCCUAGUGCUCCCCACA. . } \\
\qquad\|\|\|\| \\
\text { GGAGUACCUUCCCAAGGGGUGA }\end{array}$ \\
\hline
\end{tabular}

C

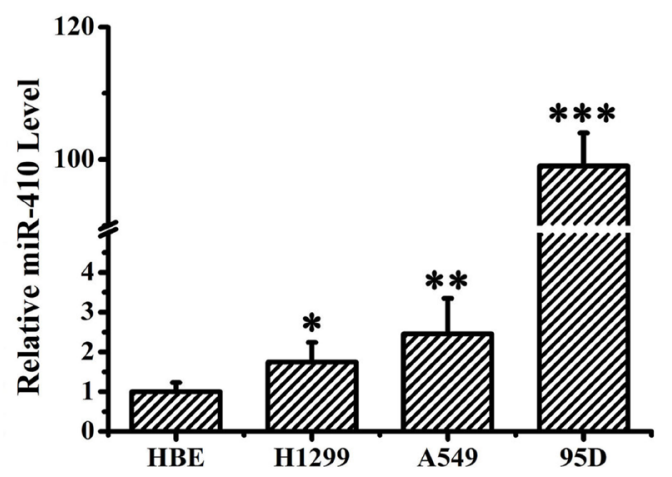

$\mathbf{E}$

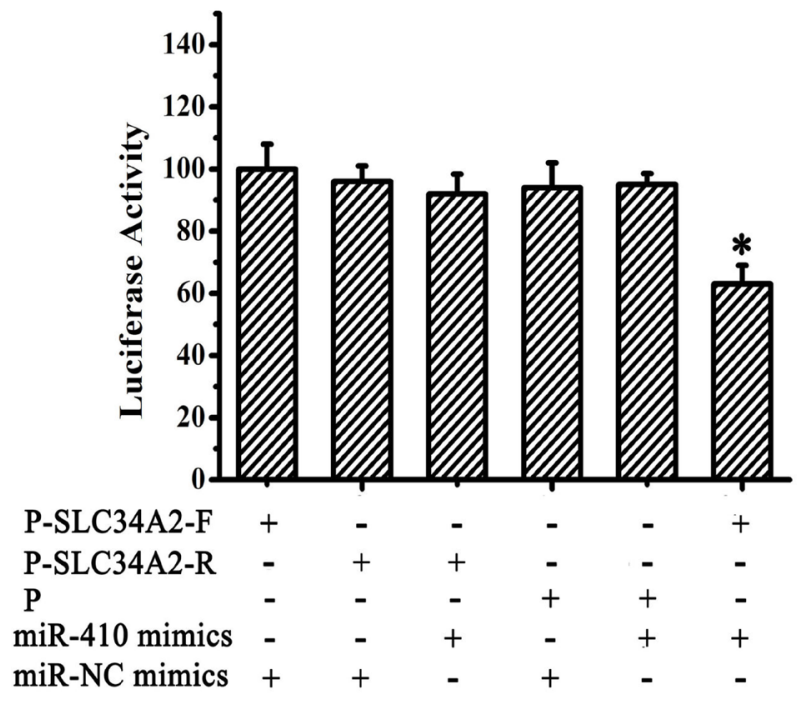

B

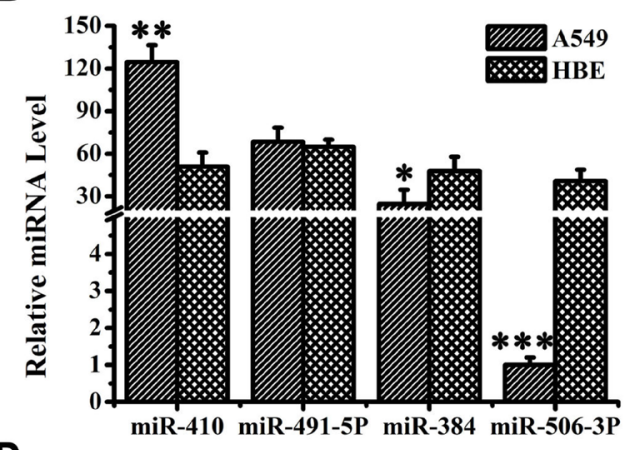

D
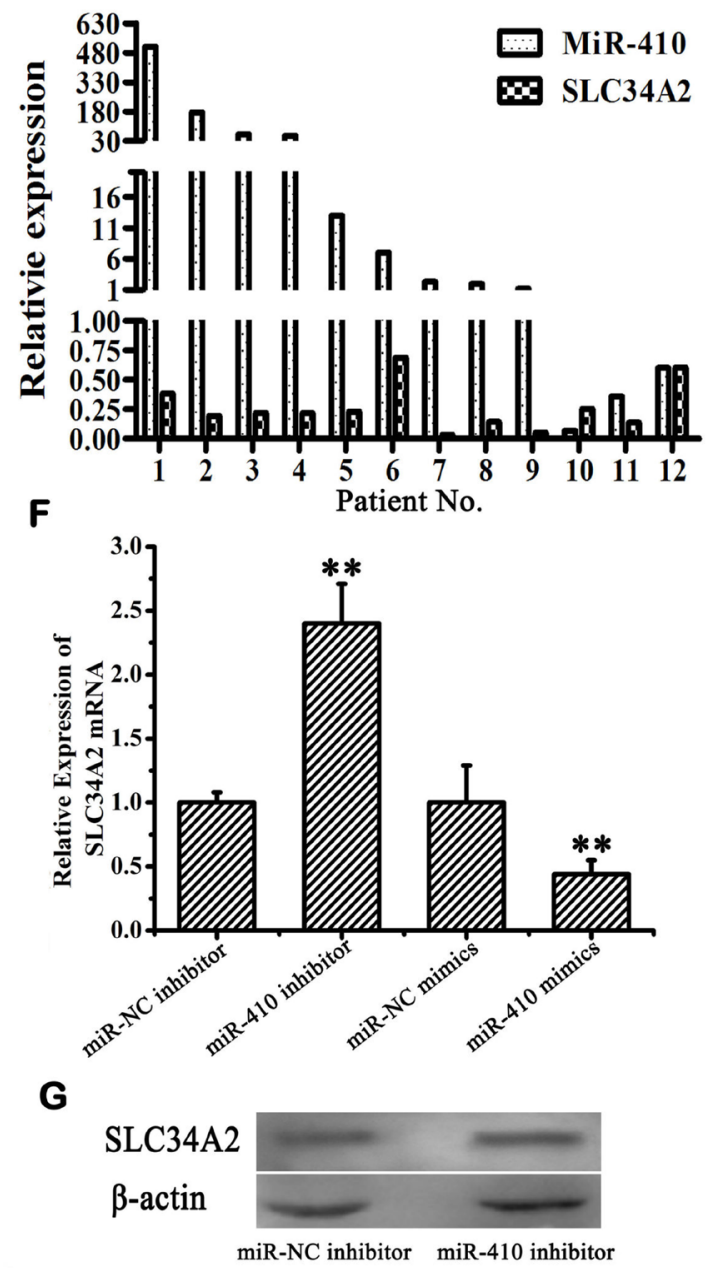

Figure 1: MiR-410 directly targeted SLC34A2. A. Four miRNAs (miR-410, miR-491-5P, miR-384 and miR-506-3P) were predicted by both algorithms (TargetScan, miRanda). The numbers indicate the nucleotide position in reference to the start of SLC34A2 3'UTR. B. The expression of miR-410, miR-491-5P, miR-384 and miR-506-3P in A549 cells was determined by qRT-PCR. C. The expressions of miR-410 in A549, 95D and H1299 cells were determined by qRT-PCR. D. Relative expression of miR-410 and SLC34A2 detected by qRTPCR in NSCLC patient tissues. Increased miR-410 expression and decreased SLC34A2 expression were indicated in 9 of 12 NSCLC patient tissues compared with adjacent non-tumorous tissues. E. Luciferase reporter assay was performed to confirm the miR-410 binding to the 3'UTR of SLC34A2. The luciferase activity was detected after co-transfection with luciferase reporter plasmids (Pmir-SLC34A2 3'UTR-F, P-SLC34A2-F; Pmir-SLC34A2 3'UTR-R, P-SLC34A2-R), with miR-410 mimics/NC or miR-410 inhibitors/NC in HEK293 cells. F. Realtime PCR was performed to detect SLC34A2 mRNA level after transfection of miR-410 inhibitors or miR-410 mimics with corresponding control in A549 cells. G. Western blotting was performed to detect SLC34A2 protein level after transfection of miR-410 inhibitors with corresponding control in A549 cells. For miR-410 and SLC34A2 mRNA expression detected by qRT-PCR, U6 and $\beta$-actin were used as internal control respectively. For SLC34A2 protein expression detected by western blotting, $\beta$-actin was used as internal loading control. Data are presented as the mean value \pm SD from triplicate experiments. $*, p<0.05 ; * *, p<0.01$. 
up-regulated or down-regulated after transfection with miR-410 mimics or inhibitors compared with respective $\mathrm{NC}$ in both A549 and 95D cell lines (Figure 2A and 2B) $(p<0.05)$. MTT assay showed cell growth was greatly enhanced after transfecting with miR-410 mimics compared with the matched NC in both A549 and 95D
A

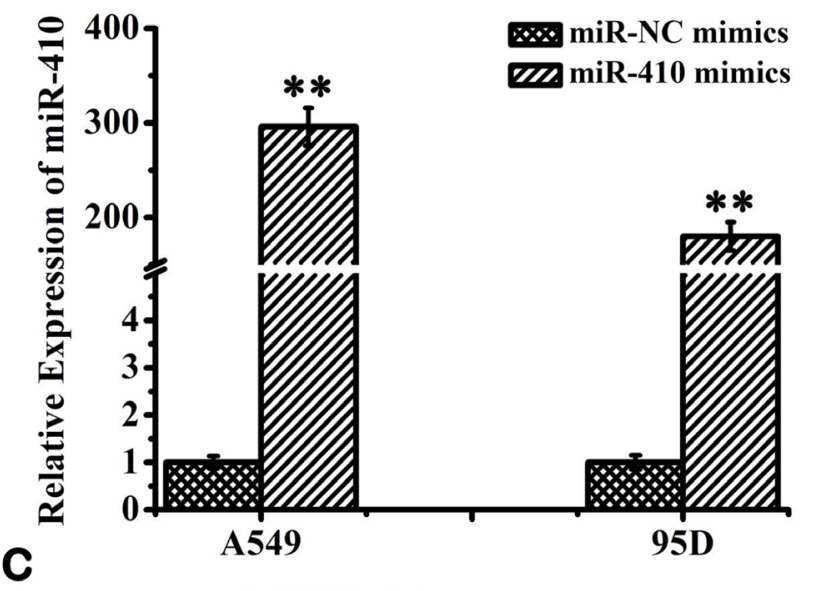

B
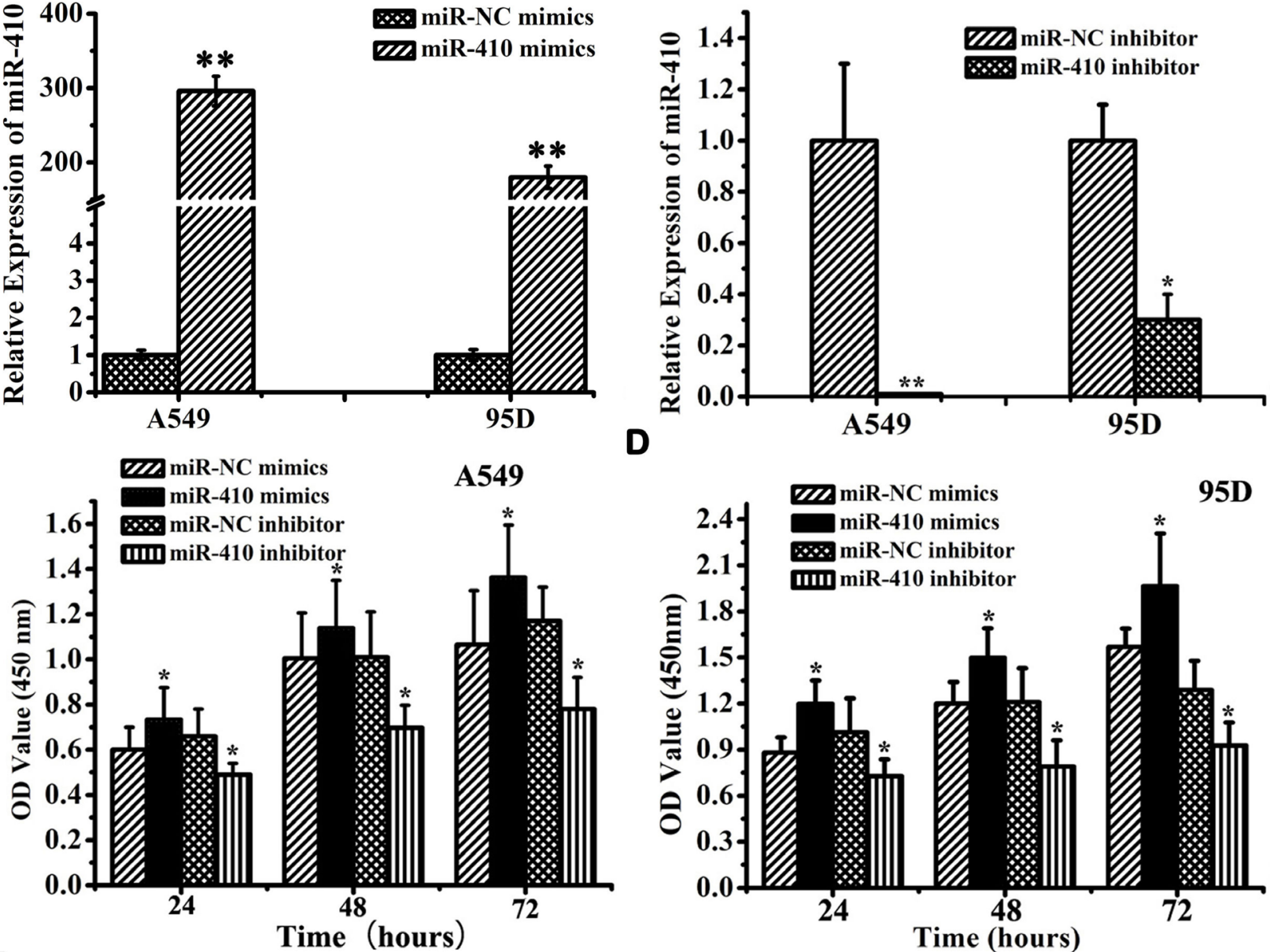

$\mathbf{E}$

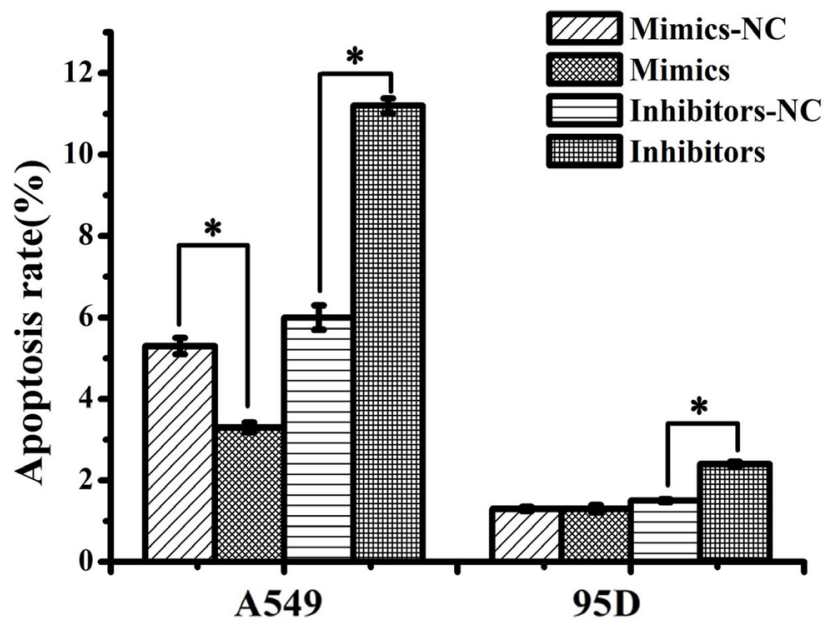

Figure 2: MiR-410 promoted cell proliferation and inhibited apoptosis of NSCLC cells. A. and B. Real-time RT-PCR showed miR-410 expression in A549 and 95D cells after transfection of miR-410 inhibitors/NC A. or miR-410 mimics/NC B.. C. and D. MTT assay displayed that overexpression or inhibition of miR-410 promoted or prohibited cell growth of A549 C. and 95D D. cells. E. Overexpression or inhibition of miR-410 suppressed or enhanced apoptosis of A549 and 95D cells. Data are presented as the mean value \pm SD from triplicate experiments. *, $p<0.05 ; * *, p<0.01$. 
A

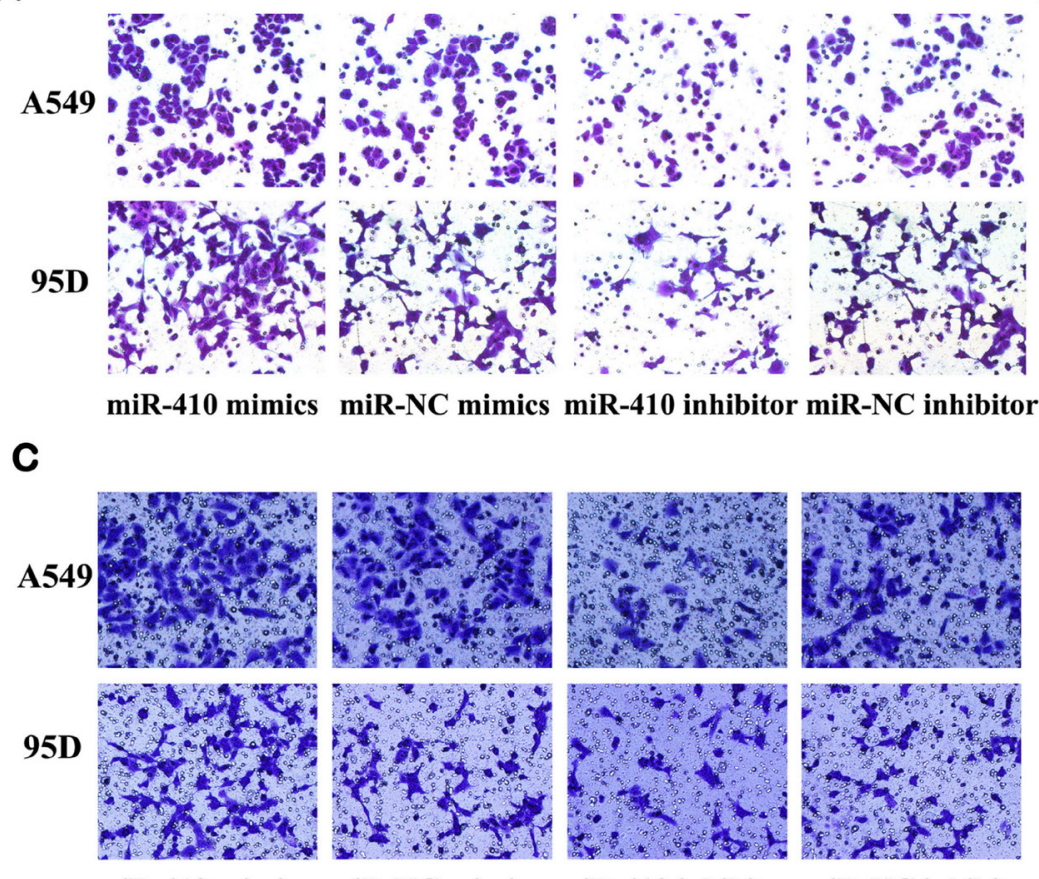

miR-410 mimics miR-NC mimics miR-410 inhibitor miR-NC inhibitor
B
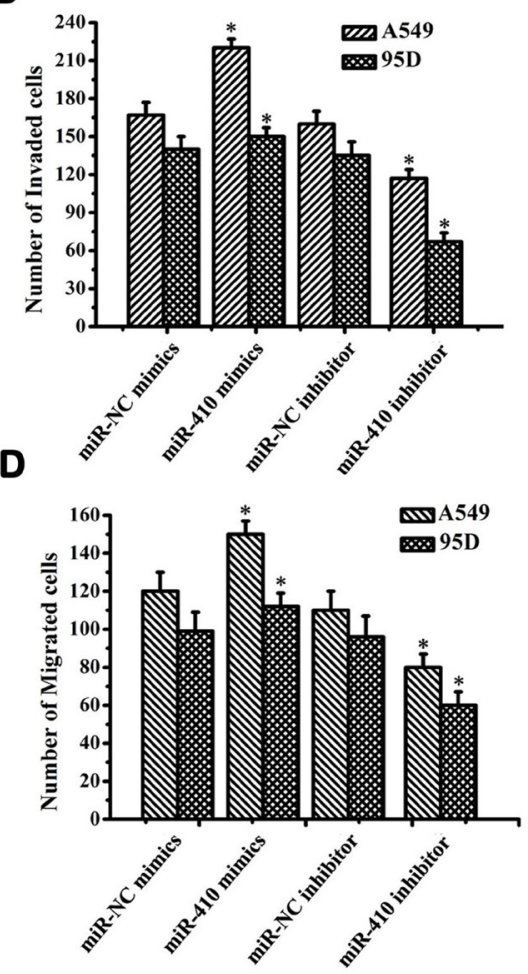

E

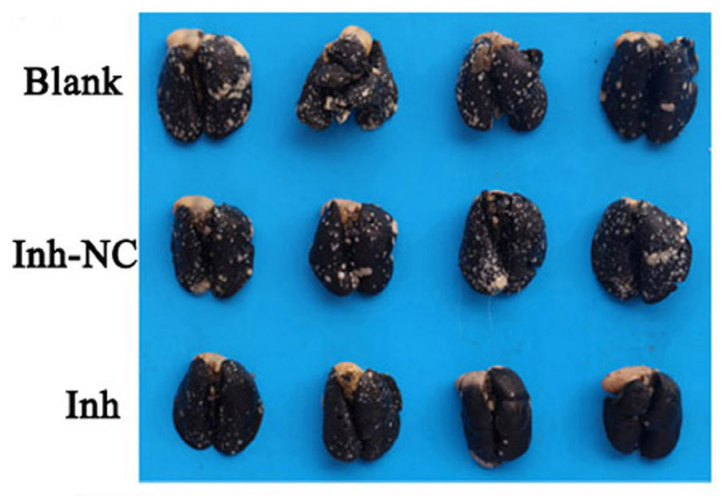

$\mathbf{F}$

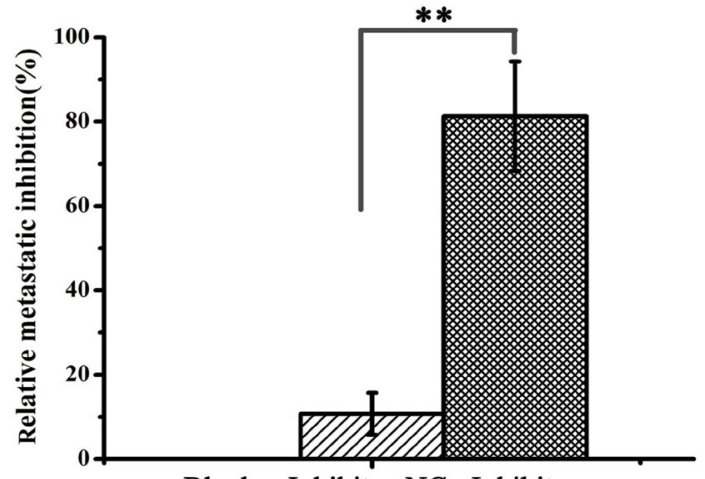

G

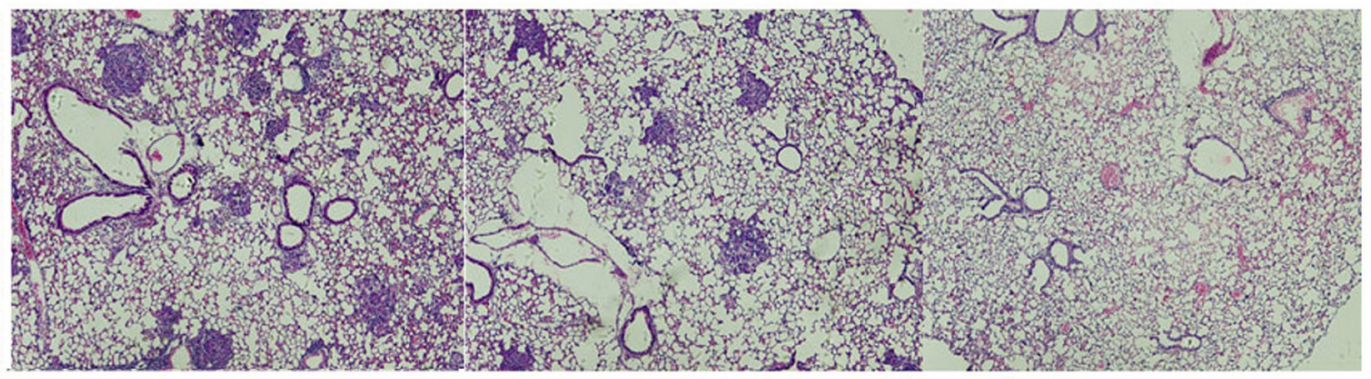

Blank

Inhibitor-NC

Inhibitor

Figure 3: MiR-410 promoted invasion and migration of NSCLC cells in vivo and in vitro. A. and B. Transwell assay showed overexpression or inhibition of miR-410 promoted or prohibited invasion of A549 and 95D cells (100×). C. and D. Millicell assay showed that overexpression or inhibition of miR-410 promoted or prohibited migration of A549 and 95D cells (100×). E. Metastatic tumors in the lungs. About 5 weeks later, mice were anesthetized and their lungs were filled with India ink to examine the number of metastasis nodules. F. Relative inhibition of metastasis of lymph node. The percent of metastatic inhibition was calculated by comparing with A549-treated blank control. G. Representative images of H\&E staining of the lung tissues of mice $(40 \times)$. Data are presented as the mean value \pm SD from triplicate experiments. *, $p<0.05 ;{ }^{* *}, p<0.01$. 
cells (Figure 2C and 2D) $(p<0.05)$. On the contrary, cell growth was greatly inhibited after transfection with miR410 inhibitors compared with the NC in both A549 and 95D cells (Figure $2 \mathrm{C}$ and $2 \mathrm{D})(p<0.05)$. To explore the possible mechanism of miR-410 promoting cell growth, we performed apoptotic analysis. Apoptotic assay via FACS showed that apoptotic rate was reduced in cells transfected with miR-410 mimics than that of NC, while conversely, apoptotic rate was elevated in cells transfected with miR-410 inhibitors than that of NC (Figure 2E) ( $p$ $<0.05)$. These results suggested that miR-410 could promote cell proliferation and inhibited apoptosis of
NSCLC cells in vitro. Next, we determined the in vitro effects of miR-410 on invasion and migration in A549 and 95D cells. By in vitro Transwell assay, we observed cell invasion were significantly impaired after transfecting with miR-410 inhibitors, and enhanced after transfecting with miR-410 mimics compared with respective scramble control in A549 and 95D cells (Figure 3A and 3B) $(p<$ $0.05)$. In vitro Millicell assay displayed cell migration was impaired after transfecting with miR-410 inhibitors and strengthened after transfecting with miR-410 mimics compared with respective scramble control in both A549 and 95D cells (Figure 3C and 3D) $(p<0.05)$.
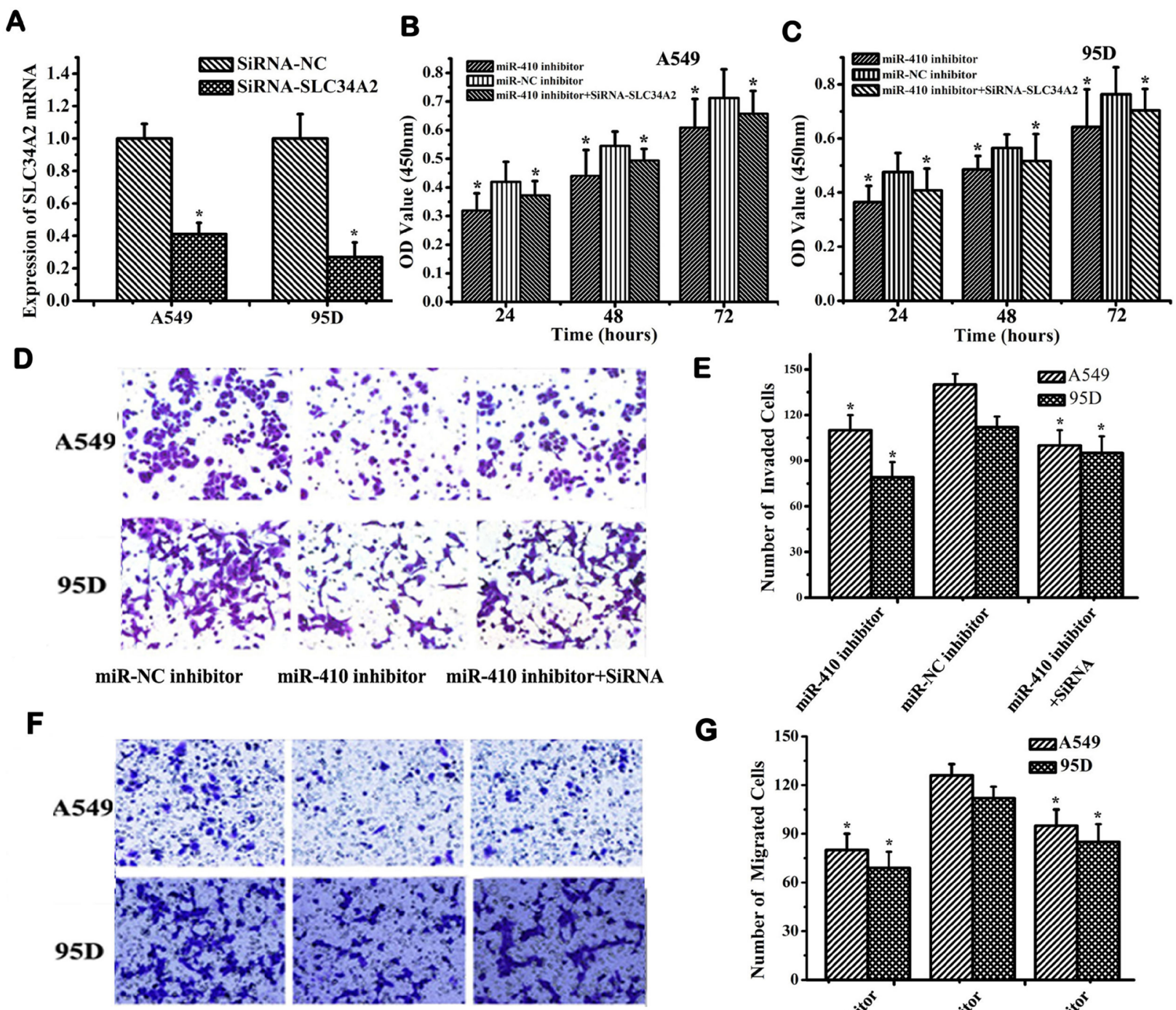

G

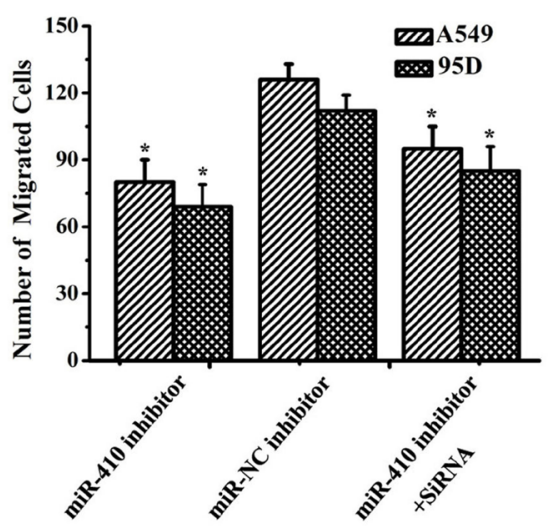

Figure 4: MiR-410 promoted proliferation, invasion and migration of NSCLC cells through targeting SLC34A2 in vitro. A. QRT-PCR detection of SLC34A2 mRNA in NSCLC A549 and 95D cells after transfecting with siRNA-SLC34A2/siRNA-NC. B. and C. MTT assay showed that inhibition of cell proliferation was partly restored in A549 B. and 95D C. cells after co-transfecting with siRNA-SLC34A2 and miR-410 inhibitor compared with that of cells transfected with miR-410 inhibitor. Transwell D. and E. and Millicell F. and G. assay indicated that inhibition of cell invasion and migration was partially restored in A549 and 95D cells after co-transfecting with siRNA-SLC34A2 and miR-410 inhibitor compared with that of cells transfected with miR-410 inhibitor (100×). Data are presented as the mean value $\pm \mathrm{SD}$ from triplicate experiments. ${ }^{*}, p<0.05 ; * *, p<0.01$. 
To further investigate the role of miR-410 on the growth and metastasis of NSCLC in vivo, we firstly established the miR-410 stable knockdown cells (INHLV) and relevant scrambled control cells (INH-NC-LV) in A549 cell lines. Then, we injected these cells into mice via tail vain to build lung metastasis nude mouse model. About 10 weeks later, lungs of five mice in each group were injected intratracheally with India ink and fixed in AAF solution ( $85 \%$ ethanol, $10 \%$ acetic acid, $5 \%$ formalin) to count the number of metastatic tumor nodules on lung surfaces. We firstly observed that tumor metastasis nodules in the lungs of mice reduced by $71.6 \%$ in mice treated with miR-410 stable knockdown cells INH-LV compared with scrambled control cells INH-NC-LV (Figure 3E and 3F) ( $p<0.01)$. And the metastasis nodules were also bigger in mice treated with miR-410 stable knockdown cells INH$\mathrm{LV}$ than those of mice treated with scrambled control cells INH-NC-LV (Figure 3E). Consistently, H\&E staining of lung tissue sections also displayed that the lungs of the mice treated with miR-410 stable knockdown A549 cells had much fewer nodules, and most of the lungs were out of tumor nodules (Figure 3G). These results confirmed that miR-410 promoted growth and metastasis of NSCLC both in vitro and in vivo.

\section{MiR-410 promoted proliferation, invasion and migration by down-regulating $S L C 34 A 2$ in NSCLC cells}

To further investigate whether miR-410-activating cellular effects were mediated through down-regulation of SLC34A2 in NSCLC cells, miR-410 inhibitors were transfected into A549 and 95D cells with or without siRNA-SLC34A2 and subsequently scored for cell proliferation, migration and invasion. Firstly, SLC $34 A 2$ mRNA was detected to check the knockdown efficiency of siRNA-SLC34A2 in A549 and 95D cells before transfection. The expression levels of SLC34A2 mRNA in siRNA-SLC34A2-transfected cells were significantly decreased compared with that of siRNA-NC-transfected cells (Figure 4A). Cell proliferation was inhibited in cells transfected with miR-410 inhibitors, while partly enhanced when cells were cotransfected with miR-410 inhibitors and siRNA-SLC34A2 compared with their respective NC control via MTT assay (Figure 4B and 4C). Similarly, the effects on cell migration and invasion were also checked using Millicell and Transwell assay. Cell migration and invasion were inhibited in cells transfected with miR-410 inhibitors, while partly promoted when cells were cotransfected with miR-410 inhibitors and siRNASLC34A2 compared with their respective NC control (Figure 4D, 4E and Figure 4F, 4G) $(p<0.05)$. These results proved that miR-410 promoted proliferation, invasion and migration in NSCLC cells partially dependent on downregulation of SLC34A2 in vitro.

\section{Increased expression of $\mathrm{miR}-410$ and reduced expression of $S L C 34 A 2$ frequently existed in NSCLC tumor tissues}

To determine the clinicopathological significance of the miR-410 and SLC34A2 aberration, we evaluated
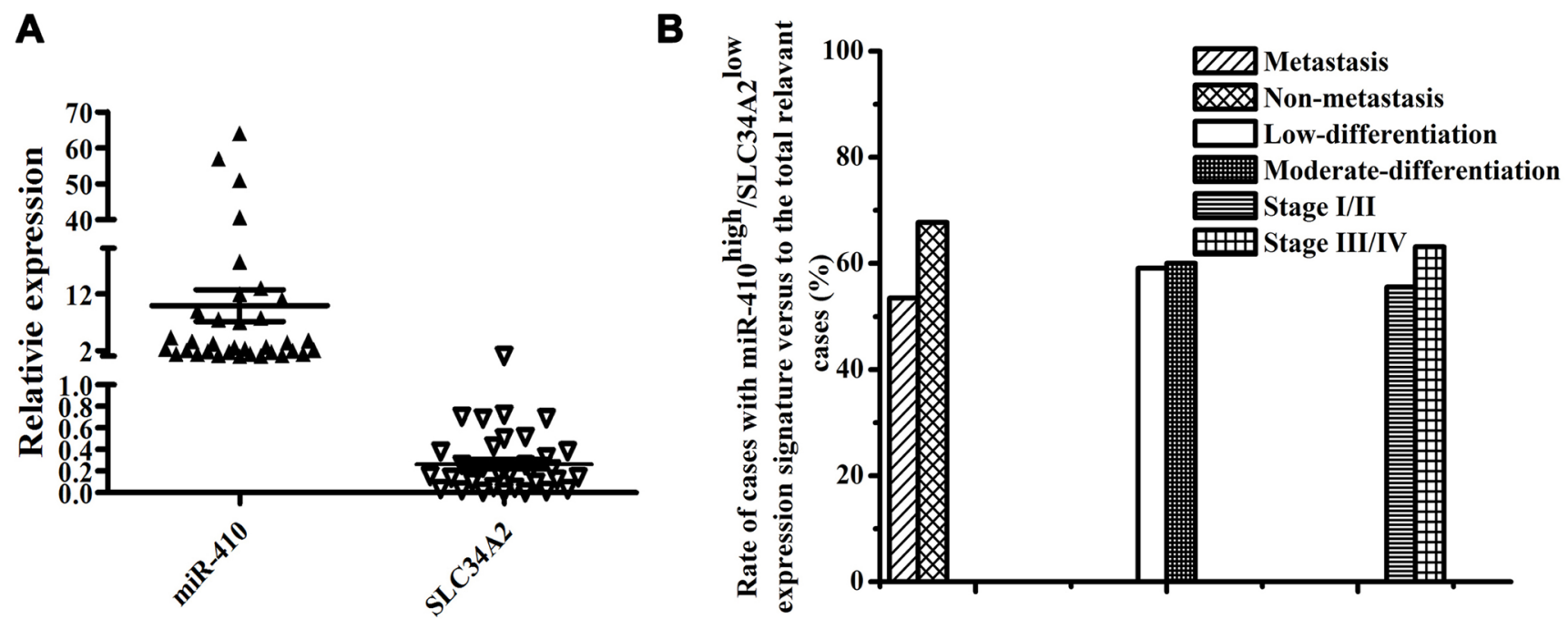

Figure 5: MiR-410 was highly expressed while SLC34A2 was lowly expressed in NSCLC tumor tissues. A. The miR410 expression was statistically higher while SLC34A2 expression was considerably lower in 45 of 75 pairs of NSCLC tissues compared with their matched non-tumorous tissues. The expression level of miR-410 and SLC34A2 were detected in 75 pairs of NSCLC frozen tissues and the adjacent non-tumorous tissues by qRT-PCR, and in 45 pairs of NSCLC tumor tissues that miR-410 expression levels were remarkably higher while $S L C 34 A 2$ expression levels were significantly lower. U6 small nuclear RNA and $\beta$-actin were used as internal control respectively. B. MiR-410 $0^{\text {high }} / S L C 34 A 2^{\text {low }}$ expression signature in NSCLC tumor tissues might not be correlated to the metastasis, differentiation or histopathological stage of NSCLC. *, $p<0.05 ; * *, p<0.01$. 
the mRNA expression of miR-410 and SLC34A2 in 75 pairs of frozen human NSCLC tumor tissues and adjacent non-tumorous lung tissues using qRT-PCR. MiR-410 or SLC34A2 expression was not significantly associated with age and gender of the NSCLC patients (Table 1). However, miR-410 expression levels were remarkably higher while SLC34A2 expression levels were significantly lower in 45 of 75 pairs of human NSCLC tumor tissues $(45 / 75=60.0 \%)$ than that of their matched adjacent non-tumorous tissues respectively (Table 1, Figure 5A). Moreover, the rate of miR-410 $10^{\text {high }} / S L C 34 A 2^{\text {low }}$ cases with tumor metastasis was lower than that of $\mathrm{miR}-410^{\text {high }} / S L C 34 A 2^{\text {low }}$ cases without tumor metastasis, while there was no statistical significance $(p>0.05)$ (Figure $5 \mathrm{~B})$. In addition, the rate of miR-410 high $/ S L C 34 A 2^{\text {low }}$ cases with low-differentiated tumors was not significantly different from that of miR-
A

B-catenin

Dvl2

Gsk3ß

Mimics

Mimics-NC

Inhibitors

Inhibitors-NC

C

Dvl2

Gsk3ß

$\beta$-catenin

$\beta$-actin

p-SLC34A2

p3.1

SIRNA-SLC34A2

SiRNA-NC

E

Dvl2

Gsk3ß

$\beta$-catenin

$\beta$-actin

SIRNA-SLC34A2

miR-410 inhibitors

miR-410 inhibitors-NC

SiRNA-SLC34A2 +

miR-410 inhibitors
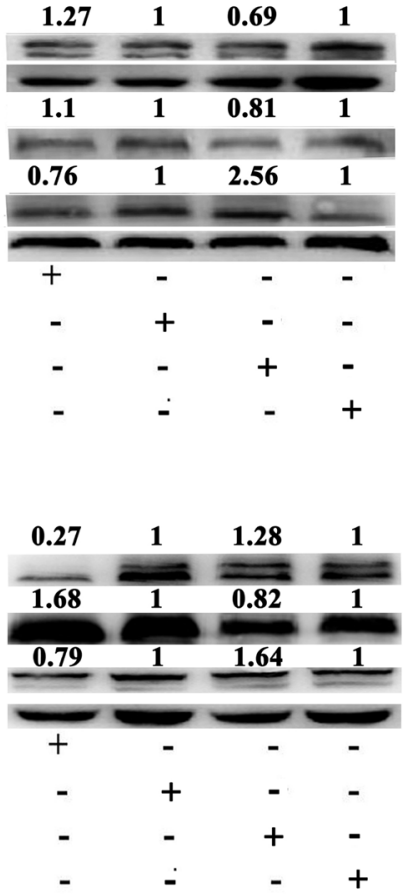

D

Dvl2
Gsk3 $\beta$
$\beta$-catenin
$\beta$-actin
p-SLC34A2
p3.1
siRNA-SLC34A2
siRNA-NC

$\mathbf{F}$

Dvl2

Gsk3ß

$\beta$-catenin

$\beta$-actin

SIRNA-SLC34A2
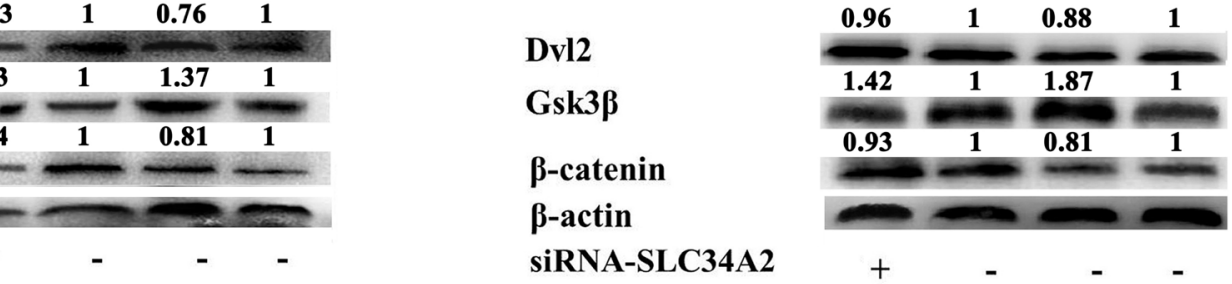

$-\quad-\quad+\quad-$

$-\quad+\quad+$

$\begin{array}{lll}- & - & + \\ + & - & -\end{array}$
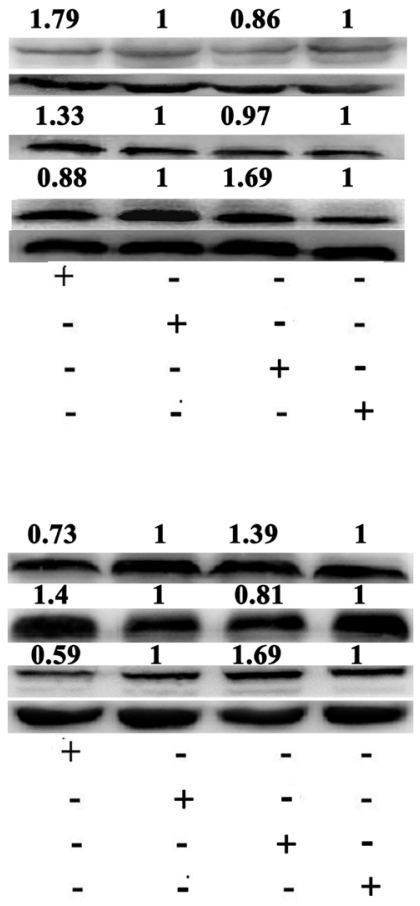

miR-410 inhibitor miR-410 inhibitors-NC SiRNA-SLC34A2 + miR-410 inhibitors

Figure 6: MiR-410 functioned by targeting SLC34A2 through Wnt/ $\beta$-catenin pathway in NSCLC cells. (A and B) Western blotting analysis of $\beta$-catenin, DVL2 and Gsk3 $\beta$ protein expression in A549 A. and 95D B. cells after transfecting with miR-410 inhibitors/NC or mimics/NC. Overexpression of miR-410 significantly up-regulated $D V L 2$ and $\beta$-catenin respectively, and down-regulated Gsk3 $\beta$, while inhibition of miR-410 down-regulated DVL2 and $\beta$-catenin respectively, and up-regulated Gsk3 $\beta$ in both A549 A. and 95D B. cells compared with their respective control. (C and D) Western blotting analysis of $\beta$-catenin, DVL2 and Gsk3 $\beta$ protein expression in A549 C. and 95D D. cells after cotransfecting with p3.1-SLC34A2/p3.1 or siRNA-SLC34A2/siRNA-NC. Overexpression of SLC34A2 significantly down-regulated $D V L 2$ and $\beta$-catenin respectively, and up-regulated Gsk3 $\beta$, while inhibition of $S L C 34 A 2$ up-regulated $D V L 2$ and $\beta$-catenin respectively, and down-regulated $G s k 3 \beta$ in both A549 C. and 95D D. cells compared with their respective control. (E and F) Western blotting analysis of $\beta$-catenin, DVL2 and Gsk3 $\beta$ protein expression in A549 E. and 95D F. cells after cotransfecting with miR-410 inhibitors and siRNA-SLC34A2. Down-regulation of DVL2 and $\beta$-catenin, and up-regulation of Gsk3 $\beta$ were partly impaired in both A549 E. and 95D F. cells after cotransfecting with miR-410 inhibitors/NC and siRNA-SLC34A2 compared with that of cells transfecting with miR-410 inhibitors/NC. *, $p<0.05 ; * *, p<0.01$, significant difference vs NC control. 
$410^{\text {high }} / S L C 34 A 2^{\text {low }}$ cases with moderate-differentiated tumors $(p>0.05)$, and the rate of miR-410 $0^{\text {high }} / S L C 34 A 2^{\text {low }}$ cases with tumors in stage I/II was also not significantly different from that of $\mathrm{miR}-410^{\mathrm{high}} / \mathrm{SLC} 34 \mathrm{~A} 2^{\text {low }}$ cases with tumors in stage III/IV $(p>0.05)$ (Figure 5B). Therefore, the expression of miR-410 and SLC34A2 were conversely correlated, and the miR-410 $0^{\text {high }} / S L C 34 A 2^{\text {low }}$ expression signature frequently existed in human NSCLC tumor tissues but might not be correlated to the metastasis, differentiation or histopathological stage of NSCLC.
MiR-410 functioned as oncogene by downregulating SLC34A2 via activating Wnt/ßcatenin pathway in NSCLC cells

$\mathrm{Wnt} / \beta$-catenin pathway played a significant role in lung cancer tumorgenesis. To explore the mechanism of how miR-410 functioning via targeting SLC34A2 in NSCLC cells, miR-410 inhibitors/NC or miR-410 mimics/ NC were firstly transfected into A549 and 95D cells and western blotting was performed to detect the change of core protein levels of $\mathrm{Wnt} / \beta$-catenin pathway. We found that overexpression of miR-410 significantly upregulated the protein expression of DVL2 (1.1 fold and 1.33 fold respectively) and $\beta$-catenin (1.27 fold and 1.79

A

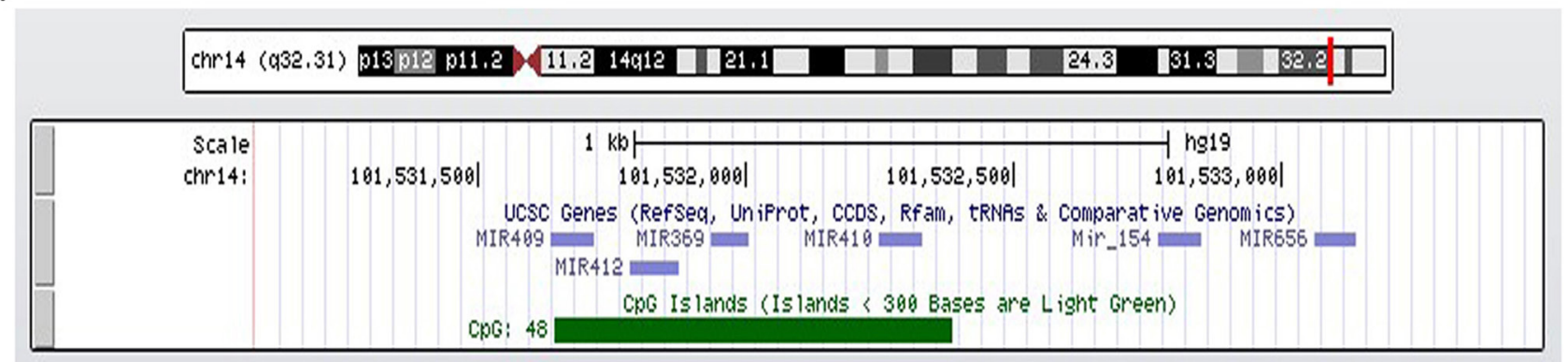

B

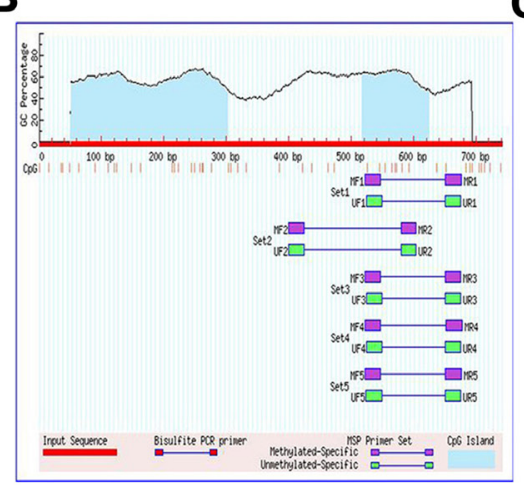

D

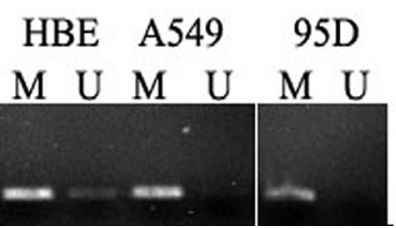

C

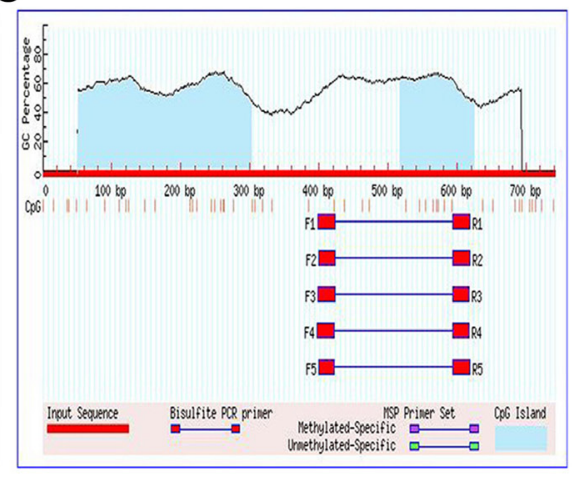

E

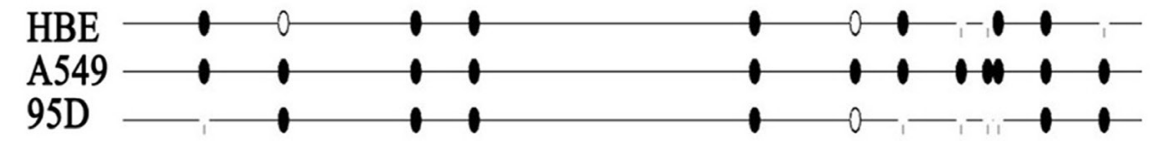

Figure 7: Abnormal expression of miR-410 is not regulated by methylation or acetylation in NSCLC cells. A. CpG island located in the gene locus of miR-410 according to UCSC database (http://genome.ucsc. edu/cgi-bin/hgGateway). Blue areas: predicted CpG islands (Locus: chr14: 101531644-101532384, GC content 67.2\%, Obs/Exp value 0.8). (B and C) Primers were designed to cover the CpG islands upward miR-410 for methylation analysis. Primer sets for MSP B. and BSP C. according to MethPrimer (http://www.urogene. org/methprimer/index 1.html). D. MSP results detected by 2\% agarose gel electrophoresis in A549, 95D and HBE cells. U, unmethylated; M, methylated. HBE, human bronchial epithelial cells. The result indicated that miR-410 was partly methylated in normal HBE and 95D cells, but almost totally methylated in A549 cells. E. Bisulfite sequencing analysis of miR-410 in A549, 95D and HBE cells. Black dot, methylated; White dot, unmethylated. The result of bisulfite sequencing (BSP) showed that all the 12 CpGs sites sequenced were completely methylated in A549 cells, and 6 of 12 CpGs sites (50\%) were methylated in 95D cells, and 7 of 12 CpGs sites (58.3\%) were methylated in HBE cells, in consistent with the result of MSP. F. Expression levels of miR-410 were detected by qRT-PCR in A549 and 95D cells after treatment with DNA methylation inhibitor 5'-aza-2'-deoxycytidine (DAC) and/or histone deacetylase (HDAC) inhibitor trichostatin A (TSA). Data are expressed as means $\pm \mathrm{SD}$ of triplicate assays. ${ }^{*}, p<0.05 ;^{* *}, p<0.01$, significant difference vs untreated group. 
Table 1: Patient clinical features, miR-410 and SLC34A2 expressions profile

\begin{tabular}{|c|c|c|c|c|c|c|c|c|}
\hline $\begin{array}{l}\text { Patient } \\
\text { No. }\end{array}$ & Gender & Age & Differentiation & $\begin{array}{l}\text { Metastatic or } \\
\text { non-metastatic }\end{array}$ & $\begin{array}{l}\text { Histological } \\
\text { grade }\end{array}$ & $\begin{array}{l}\text { Clinical } \\
\text { stage }\end{array}$ & $\begin{array}{l}\text { Normalized miR-410 } \\
\text { Expression in tumor } \\
\text { tissues relative } \\
\text { to adjacent non- } \\
\text { tumorous tissues }\end{array}$ & $\begin{array}{l}\text { Normalized } \\
\text { SLC34A2 } \\
\text { expression in tumor } \\
\text { tissues relative } \\
\text { to adjacent non- } \\
\text { tumorous tissues }\end{array}$ \\
\hline 1 & $\mathrm{M}$ & 45 & Medium & $\mathrm{N}$ & A & IIIB & 1.755 & 0.7214 \\
\hline 2 & $\mathrm{M}$ & 68 & Low & $\mathrm{Y}$ & $\mathrm{A}$ & IIA & 0.5587 & 2.1412 \\
\hline 3 & $\mathrm{~F}$ & 47 & Low & $\mathrm{Y}$ & $\mathrm{A}$ & IIIB & 0.6028 & 1.7791 \\
\hline 4 & $\mathrm{M}$ & 51 & Low & $\mathrm{Y}$ & A & IIIA & 0.1763 & 1.4826 \\
\hline 5 & $\mathrm{M}$ & 56 & Low & $\mathrm{N}$ & $\mathrm{A}$ & IB & 0.4247 & 0.7351 \\
\hline 6 & $\mathrm{M}$ & 47 & Low & $\mathrm{N}$ & $\mathrm{A}$ & IIA & 7.4267 & 0.703 \\
\hline 7 & $\mathrm{~F}$ & 65 & Low & $\mathrm{Y}$ & A & IIA & 3.6209 & 0.2017 \\
\hline 8 & $\mathrm{~F}$ & 25 & Low & $\mathrm{Y}$ & $\mathrm{A}$ & IV & 1.1366 & 2.2838 \\
\hline 9 & $\mathrm{~F}$ & 71 & Medium & $\mathrm{Y}$ & $\mathrm{A}$ & IIA & 0.1811 & 0.561 \\
\hline 10 & $\mathrm{M}$ & 67 & Low & $\mathrm{Y}$ & $\mathrm{A}$ & IV & 0.4827 & 1.9724 \\
\hline 11 & $\mathrm{~F}$ & 54 & Low & $\mathrm{N}$ & A & IB & 0.7007 & 1.523 \\
\hline 12 & $\mathrm{~F}$ & 72 & Low & $\mathrm{Y}$ & $\mathrm{A}$ & IIIB & 0.2345 & 1.351 \\
\hline 13 & $\mathrm{M}$ & 43 & Low & $\mathrm{Y}$ & $\mathrm{A}$ & IIB & 1.3632 & 0.38 \\
\hline 14 & $\mathrm{~F}$ & 62 & Low & $\mathrm{Y}$ & $\mathrm{A}$ & IIIA & 1.1689 & 4.0905 \\
\hline 15 & $\mathrm{~F}$ & 48 & Low & $\mathrm{N}$ & $\mathrm{A}$ & IIA & 0.2972 & 2.7211 \\
\hline 16 & $\mathrm{~F}$ & 54 & \begin{tabular}{|l|} 
Low \\
\end{tabular} & $\mathrm{Y}$ & $\mathrm{A}$ & IIIA & 51.0135 & 0.3841 \\
\hline 17 & $\mathrm{~F}$ & 53 & Medium & $\mathrm{N}$ & $\mathrm{A}$ & IA & 0.3602 & 0.1363 \\
\hline 18 & $\mathrm{~F}$ & 74 & Low & $\mathrm{Y}$ & $\mathrm{A}$ & IIA & 0.6011 & 0.6031 \\
\hline 19 & $\mathrm{M}$ & 71 & Low & $\mathrm{N}$ & $\mathrm{A}$ & IB & 64.0105 & 0.2201 \\
\hline 20 & $\mathrm{~F}$ & 52 & Low & $\mathrm{N}$ & A & IB & 2.3203 & 0.0344 \\
\hline 21 & $\mathrm{~F}$ & 59 & Low & $\mathrm{Y}$ & $\mathrm{A}$ & IIIB & 1.2101 & 0.0516 \\
\hline 22 & $\mathrm{~F}$ & 79 & Low & $\mathrm{N}$ & $\mathrm{A}$ & IB & 17.6035 & 0.195 \\
\hline 23 & $\mathrm{~F}$ & 74 & Low & $\mathrm{N}$ & $\mathrm{A}$ & IB & 7.0731 & 0.6887 \\
\hline 24 & $\mathrm{~F}$ & 61 & Low & $\mathrm{Y}$ & $\mathrm{A}$ & IIIA & 13.0809 & 0.2298 \\
\hline 25 & $\mathrm{~F}$ & 69 & \begin{tabular}{|l|} 
Low \\
\end{tabular} & $\mathrm{N}$ & $\mathrm{A}$ & IIB & 2.0741 & 0.1422 \\
\hline 26 & $\mathrm{~F}$ & 64 & Medium & $\mathrm{N}$ & A & IB & \begin{tabular}{|l|}
57.0217 \\
\end{tabular} & 0.215 \\
\hline 27 & $\mathrm{M}$ & 67 & Low & $\mathrm{N}$ & $\mathrm{A}$ & IB & 0.0711 & 0.2539 \\
\hline 28 & $\mathrm{~F}$ & 73 & Low & $\mathrm{Y}$ & $\mathrm{A}$ & IIIB & \begin{tabular}{|l|}
1.4009 \\
\end{tabular} & 1.0359 \\
\hline 29 & $\mathrm{M}$ & 64 & \begin{tabular}{|l|} 
Medium \\
\end{tabular} & $\mathrm{N}$ & $\mathrm{A}$ & IB & 0.2662 & 1.5619 \\
\hline 30 & $\mathrm{M}$ & 49 & Low & $\mathrm{Y}$ & $\mathrm{A}$ & IIIA & 1.7752 & 0.185 \\
\hline 31 & $\mathrm{M}$ & 62 & Medium-high & $\mathrm{N}$ & $\mathrm{A}$ & IIIA & 0.8688 & 0.6332 \\
\hline 32 & $\mathrm{M}$ & 73 & Medium & $\mathrm{Y}$ & $\mathrm{A}$ & IIIA & 0.0588 & 1.6946 \\
\hline 33 & $\mathrm{~F}$ & 70 & Medium & $\mathrm{Y}$ & $\mathrm{A}$ & IIB & 11.9298 & 0.2562 \\
\hline 34 & $\mathrm{~F}$ & 62 & Medium & $\mathrm{N}$ & $\mathrm{A}$ & IIA & 0.0783 & 5.3182 \\
\hline 35 & $\mathrm{~F}$ & 62 & \begin{tabular}{|l|} 
Medium-high \\
\end{tabular} & $\mathrm{N}$ & A & IIIA & 0.8982 & 2.1794 \\
\hline 36 & $F$ & 28 & Low & $\mathrm{N}$ & $\mathrm{A}$ & IIIA & 1.4345 & 0.1355 \\
\hline 37 & $\mathrm{~F}$ & 57 & Low & $\mathrm{Y}$ & $\mathrm{A}$ & IIB & 0.5228 & 0.2823 \\
\hline 38 & $\mathrm{M}$ & 61 & \begin{tabular}{|l} 
Medium \\
\end{tabular} & $\mathrm{N}$ & A & IB & 2.6379 & 0.0468 \\
\hline 39 & $\mathrm{M}$ & 63 & Medium & \begin{tabular}{|l}
$\mathrm{Y}$ \\
\end{tabular} & $\mathrm{A}$ & IIA & 0.1181 & 0.828 \\
\hline 40 & $\mathrm{M}$ & 48 & \begin{tabular}{|l|} 
Low \\
\end{tabular} & $\mathrm{Y}$ & A & IIIA & 1.3259 & 2.2234 \\
\hline 41 & $\mathrm{M}$ & 41 & Medium & $\mathrm{N}$ & $\mathrm{S}$ & III & 0.4298 & 8.7846 \\
\hline 42 & $\mathrm{M}$ & 57 & Medium & $\mathrm{N}$ & S & IIB & 0.2844 & 0.8287 \\
\hline 43 & $\mathrm{M}$ & 59 & Medium & $\mathrm{N}$ & $\mathrm{S}$ & IB & 3.1964 & 0.0037 \\
\hline 44 & $\mathrm{M}$ & 76 & Low & $\mathrm{N}$ & $\mathrm{S}$ & IIIA & 4.298 & 0.1547 \\
\hline 45 & $\mathrm{M}$ & 54 & Medium & $\mathrm{N}$ & $\mathrm{S}$ & IB & 1.1705 & 0.3275 \\
\hline 46 & $\mathrm{M}$ & 63 & Medium & $\mathrm{N}$ & $\mathrm{S}$ & IIA & 0.2511 & 0.1481 \\
\hline
\end{tabular}




\begin{tabular}{|c|c|c|c|c|c|c|c|c|}
\hline 47 & $\mathrm{M}$ & 59 & Medium & $\mathrm{N}$ & $\mathrm{S}$ & IIA & 0.2843 & 0.0033 \\
\hline 48 & $\mathrm{M}$ & 56 & Medium & $\mathrm{Y}$ & $\mathrm{S}$ & IV & 0.5287 & 0.1142 \\
\hline 49 & $\mathrm{M}$ & 48 & Medium & $\mathrm{Y}$ & $\mathrm{S}$ & IIIA & 0.1802 & 0.4249 \\
\hline 50 & $\mathrm{M}$ & 61 & Medium & $\mathrm{N}$ & S & IB & 0.3567 & 0.0092 \\
\hline 51 & $M$ & 49 & Medium & $\mathrm{N}$ & S & IIIA & 1.4163 & 0.0936 \\
\hline 52 & $M$ & 49 & Low & $\mathrm{Y}$ & S & IIIA & 0.3087 & 0.0031 \\
\hline 53 & $\mathrm{M}$ & 62 & Low & Y & $\mathrm{S}$ & IIIA & 0.1055 & 0.2961 \\
\hline 54 & $\mathrm{M}$ & 65 & Low & $\mathrm{Y}$ & $\mathrm{S}$ & IIIA & 0.0692 & 0.0185 \\
\hline 55 & $\mathrm{M}$ & 55 & Low & $\mathrm{Y}$ & $\mathrm{S}$ & IIIA & 0.1646 & 0.024 \\
\hline 56 & $\mathrm{M}$ & 44 & Low & $\mathrm{Y}$ & $\mathrm{S}$ & IIA & 0.7377 & 0.0359 \\
\hline 57 & $\mathrm{M}$ & 66 & Medium & $\mathrm{N}$ & S & IIIA & 0.3227 & 0.0021 \\
\hline 58 & $\mathrm{M}$ & 55 & Low & $\mathrm{Y}$ & $\mathrm{S}$ & IIIA & 1.0529 & 0.0142 \\
\hline 59 & $\mathrm{M}$ & 50 & Medium & $\mathrm{Y}$ & $\mathrm{S}$ & IIIA & 3.3646 & 0.0067 \\
\hline 60 & $\mathrm{M}$ & 53 & Medium & $\mathrm{Y}$ & $\mathrm{S}$ & IIIA & 2.5116 & 0.0308 \\
\hline 61 & $\mathrm{M}$ & 53 & Low & $\mathrm{Y}$ & $\mathrm{S}$ & IIA & 0.0246 & 0.7127 \\
\hline 62 & $\mathrm{M}$ & 50 & Low & $\mathrm{N}$ & $\mathrm{S}$ & IB & 1.1022 & 0.0051 \\
\hline 63 & $\mathrm{M}$ & 74 & Low & $\mathrm{N}$ & $\mathrm{S}$ & IA & 1.8755 & 0.0982 \\
\hline 64 & $M$ & 58 & Low & $\mathrm{Y}$ & $\mathrm{S}$ & IIIA & 0.0394 & 0.2299 \\
\hline 65 & $\mathrm{M}$ & 55 & Medium & $\mathrm{Y}$ & $\mathrm{S}$ & IIIA & 2.3041 & 0.255 \\
\hline 66 & $\mathrm{M}$ & 41 & Low & $\mathrm{Y}$ & $\mathrm{S}$ & IIIA & 9.0098 & 0.5008 \\
\hline 67 & $\mathrm{M}$ & 40 & Medium & $\mathrm{Y}$ & $\mathrm{S}$ & IIIB & 2.0088 & 0.4269 \\
\hline 68 & $\mathrm{M}$ & 63 & Medium & $\mathrm{Y}$ & $\mathrm{S}$ & IIIA & 0.1397 & 0.6806 \\
\hline 69 & $\mathrm{M}$ & 56 & Low & $\mathrm{Y}$ & $\mathrm{S}$ & IIB & 0.0021 & 0.0075 \\
\hline 70 & $\mathrm{M}$ & 65 & Medium & $\mathrm{Y}$ & $\mathrm{S}$ & IIIA & 40.6273 & 0.1683 \\
\hline 71 & $\mathrm{M}$ & 66 & Low & $\mathrm{Y}$ & $\mathrm{S}$ & IIA & 7.7249 & 0.0222 \\
\hline 72 & $\mathrm{M}$ & 58 & Low & $\mathrm{Y}$ & S & IIIA & 11.0334 & 0.1197 \\
\hline 73 & $\mathrm{M}$ & 57 & Low & $\mathrm{Y}$ & $\mathrm{S}$ & IIIA & 3.7474 & 0.6882 \\
\hline 74 & $\mathrm{M}$ & 62 & Medium & $\mathrm{Y}$ & S & IIB & 0.6636 & 0.8524 \\
\hline 75 & M & 62 & N/A & N/A & N/A & N/A & 2.1138 & 0.5149 \\
\hline
\end{tabular}

Note: M, male; F, female; A, adenocarcinoma; S, squamous cell carcinoma; L, large cell carcinoma; Y, yes; N, no. Relative expression of miR-410 and SLC34A2 were performed by the $2^{-\Delta \Delta \mathrm{Ct}}$ method with adjacent non-tumorous lung tissues as a calibrator. Data show the means from independent analyses. Every independent analysis by Real - time PCR was carried out immediately after the RNA extraction and reverse transcribed. $\Delta \mathrm{Ct}$ obtained from real-time PCR was subjected to paired t-test $\left(\triangle \mathrm{Ct}=\mathrm{Ct}_{\mathrm{SLC} 34 \mathrm{~A} 2}-\mathrm{Ct}_{\beta-\mathrm{actin}}\right)$.

fold respectively), and down-regulated $G s k 3 \beta$ ( 0.76 fold and 0.88 fold respectively), while inhibition of miR-410 significantly down-regulated the protein expression of DVL2 ( 0.81 fold and 0.97 fold respectively) and $\beta$-catenin ( 0.69 fold and 0.86 fold respectively), and up-regulated Gsk3 $\beta$ (2.56 fold and 1.69 fold respectively) in both A549 (Figure 6A) and 95D (Figure 6B) cells. Then, we detected the effect of $S L C 34 A 2$ on the core protein levels of $\mathrm{Wnt} / \beta$ catenin pathway after transfecting with p3.1-SLC34A2/ p3.1 or siRNA-SLC34A2/siRNA-NC in A549 and 95D cells by western blotting. Conversely, overexpression of SLC34A2 significantly down-regulated the protein expression of $D V L 2$ ( 0.27 fold and 0.73 fold respectively) and $\beta$-catenin ( 0.79 fold and 0.59 fold respectively), and up-regulated $G s k 3 \beta$ (1.67 fold and 1.4 fold respectively), while inhibition of $S L C 34 A 2$ significantly up-regulated the protein expression of DVL2 (1.28 fold and 1.39 fold respectively) and $\beta$-catenin (1.64 fold and 1.69 fold respectively), and down-regulated Gsk $3 \beta$ ( 0.82 fold and
0.81 fold respectively) in both A549 (Figure 6C) and 95D (Figure 6D) cells. These data testified that the function of miR-410 and SLC34A2 in NSCLC cells were correlated to influencing $\mathrm{Wnt} / \beta$-catenin pathway.

Given that miR-410 directly targeted SLC34A2 and inhibition of miR-410 prohibited the $\mathrm{Wnt} / \beta$-catenin pathway, we next tested whether SLC34A2 interference could rescue the inhibition of $\mathrm{Wnt} / \beta$-catenin pathway by miR-410 interference in NSCLC cells. We found that down-regulation of DVL2 ( 0.76 fold and 0.88 fold respectively) were increased to 0.83 fold and 0.96 fold respectively, and down-regulation of $\beta$-catenin $(0.81$ fold and 0.79 fold respectively) were increased to 0.94 fold and 0.93 fold respectively, and up-regulation of $G s k 3 \beta$ ( 1.37 fold and 1.87 fold respectively) were decreased to 1.23 fold and 1.42 fold respectively in both A549 (Figure $6 \mathrm{E}$ ) and 95D (Figure 6F) cells after co-transfecting with miR-410 inhibitors and siRNA-SLC34A2 compared with that of transfecting with miR-410 inhibitors. These results 
validated that the molecular mechanism of miR-410 acting as oncogene through down-regulating SLC34A2 was correlated to $\mathrm{Wnt} / \beta$-catenin pathway.

\section{Abnormal expressions of miR-410 might be regulated neither by DNA methylation nor by deacetylation in NSCLC cells}

The genomic locus embedding miR-410 is surrounded by a CpG island (741 bps, CG content $57.2 \%$, Obs/Exp value 0.8) according to the Database UCSC (Figure 7A). In order to determine whether miR-410 abnormal expression was regulated by $\mathrm{CpG}$ methylation, we firstly designed several primer pairs for methylation analysis by methylation specific PCR (MSP) in A549 and 95D cells (Figure 7B and 7C). The MSP result indicated that miR-410 was partly methylated in normal HBE and 95D cells, but almost totally methylated in A549 cells (Figure 7D). Moreover, the result of bisulfite sequencing (BSP) showed that all the $12 \mathrm{CpGs}$ sites sequenced were completely methylated in A549 cells, and 6 of 12 CpGs sites $(50 \%)$ were methylated in 95D cells, and 7 of 12 CpGs sites $(58.3 \%)$ were methylated in HBE cells, in consistent with the result of MSP (Figure 7E). However, down-regulation expression of miR-410 were detected in A549 cells and 95D cells treated with DNA methylation inhibitor 5'-aza-2'-deoxycytidine (DAC) (Figure 7F). It suggested that miR-410 was not silenced by DNA methylation in A549 and 95D cells. Similarly, downregulation expression of $\mathrm{miR}-410$ was also detected in NSCLC cells treated with histone deacetylase inhibitor trichostatin A (TSA) (Figure 7F). It suggested that histone deacetylation might not be involved in regulating miR-410 expression.

\section{DISCUSSION}

In this study, we identified that miR-410 directly targeted the 3'UTR of SLC34A2 and suppressed its expression transcriptionally and post-transcriptionally, and confirmed that miR-410 promoted the proliferation, invasion and migration of NSCLC cells by downregulating SLC34A2 in vitro and in vivo. And we revealed miR-410 $0^{\text {high }} / S L C 34 A 2^{\text {low }}$ expression signature frequently existed in human NSCLC tumor tissues. We also demonstrated that miR-410 functioned as oncogene by down-regulating $S L C 34 A 2$ expression via activating $\mathrm{Wnt} / \beta$-catenin pathway.

Recent studies reported that miR-410 affected many physiological cellular processes, such as gene expression, cell proliferation, migration and invasion, etc., and might act as either tumor promoter or tumor suppressor and associated with malignant phenotypes [29-32]. Herein, our data indicated that miR-410 promoted cell proliferation, invasion and migration of NSCLC cells in vitro and in vivo. Therefore, miR-410 appealed to be an oncogene in NSCLC. Our results were consistent with the reports that miR-410 negatively regulated $\mathrm{pRb} / \mathrm{E} 2 \mathrm{~F}$ pathway by directly targeting CDK1 and was an oncogene in breast cancer [29], and that miR-410 was highly expressed in liver and colorectal tumors, and enhanced tumor cell growth by silencing FHL1 and thus served as oncomiR [33]. However, our results were converse with the reports that miR-410 was down-regulated in human gliomas. Overexpression of miR-410 in glioma cells strongly inhibited cell proliferation and invasion mediated by targeting MET [30], and that miR-410 directly targeted VEGF and inhibited cell proliferation and contributed to apoptosis in osteosarcoma cells [31], and that miR-410 was lowly expressed in gastric cancer and suppressed migration and invasion by targeting MDM2 [32]. It is likely that the discrepancy was caused by that their observations were attained in different type of tumors which have varied clinical or pathological features with that used in our study.

SLC34A2 is expressed on cell surfaces as a heavily glycosylated plasma membrane protein for mediating the transport of inorganic phosphate into epithelial cells via sodium ion co-transport $[6,7,34]$. Increased inorganic polyphosphate has been reported to promote the proliferation of human fibroblasts and human dental pulp cells [35]. This transporter has also been considered to be associated with cell differentiation [36] and may play a role in tumorigenesis [15]. However, the functional analyses of SLC34A2 in tumorigenesis have yielded contradictory results in different cancer models. SLC $34 A 2$ was highly expressed in thyroid cancer and breast cancer [3], but lowly expressed in non-small cell lung carcinomas tissues [15]. In this study, we demonstrated that SLC34A2 was directly targeted by miR-410 and inhibited by miR410 transcriptionally and post-transcriptionally, and the biological roles of miR-410 in NSCLC were mediated by down-regulating SLC34A2 in vitro and in vivo, indirectly implying SLC34A2 played as tumor suppressor in NSCLC. We showed in vitro that knockdown of SLC34A2 blocked the effect of miR-410 inhibition, which were critical to tumor cell biology, namely, proliferation, migration and invasion. In addition, the expression of miR-410 was negatively correlated with that of SLC34A2 in human NSCLC tumor tissues. It seemed that miR-410 $S L C 34 A 2^{\text {low }}$ expression signature frequently existed in NSCLC cells and patient tumor tissues, while was not statistically correlated to the clinical or pathological feature of tumor tissues. Moreover, miR-410 or SLC 34A2 alone was not statistically correlated to the clinical or pathological feature of tumor tissues as well (Data not shown). In the future, we will collect more human NSCLC tumor tissues to further statistically analyze the relationship between miR-410 $0^{\text {high }} / S L C 34 A 2^{\text {low }}$ expression signature with the histopathological features.

$\mathrm{Wnt} / \beta$-catenin signalling was involved in a wealth 
of developmental processes and the maintenance of adult tissue homeostasis by regulating cell proliferation, differentiation, migration, genetic stability and apoptosis, as well as by maintaining adult stem cells in a pluripotent state [37]. Aberrant regulation of this pathway was therefore associated with a variety of diseases, including cancer, fibrosis, et al [37]. Recent study in rats muscle cells found that miR-410 could inhibit the sFRP (Secreted frizzled-related proteins, an endogenous modulator of Wnt signaling that compete with the Wnt ligands for the binding to the Frizzled receptors expression) thereby activating $\mathrm{Wnt} / \beta$-catenin signaling pathway [38]. Our data showed miR-410 played a reverse role in regulating the expression of DVL2, $\beta$-catenin and Gsk $3 \beta$ compared with SLC34A2. And up-regulation of DVL2 and $\beta$-catenin and down-regulation of Gsk3 $\beta$ by miR-410 were partly rescued by $S L C 34 A 2$. It indicated that miR-410 activated $\mathrm{Wnt} / \beta$-catenin signaling pathway via down-regulating SLC 34A2 in NSCLC.

So far, the molecular mechanism of abnormal expression of miR-410 was poorly understood. In recent years, more and more studies showed that miRNA was regulated by epigenetic mechanisms [39]. As the main mechanisms of epigenetic, methylation and histone modifications have been shown to synergistically regulate gene expression [39]. Methylation occurs mainly in $\mathrm{CpG}$ islands of gene promoter. In a variety of tumors, methylation status of $\mathrm{CpG}$ islands in miRNA promoter was closely related to its expression and loss of function [40]. Many miRNAs which acted as tumor suppressor were inactivated because of high hypermethylation in tumor cells or tissues, while those of oncogenic miRNAs were activated for its hypomethylation [40]. In present experiment, we found an $\mathrm{CpG}$ islands in upstream of miR-410 promoter region (Locus: chr14: 101531644101532384, GC content 67.2\%, Obs/Exp value 0.8) through UCSC database, and it was hypermethylated in A549 and 95D cells compared with normal human bronchial epithelial cells through methylation-specific PCR and bisulfite sequencing. However, methylation inhibitor DAC (5-aza-2'-deoxycytidine) or histone deacetylase inhibitor TSA (Trichostatin A) treatment failed to increase miR-410 expression in both A549 and 95D cells, indicating that methylation and acetylation did not modulate the expression of miR-410. Therefore, we inferred some other unknown factors but methylation or deacetylation were involved in regulating the expression of miR-410, such as specific transcription factor or long noncoding RNA or some other activating factors etc. In the next plan, we will strive to use comprehensive approaches, such as transcription factor or miRNA epigenome arrays etc. to further elucidate its regulating mechanism.

In conclusion, miR-410 could act as oncogene in the development and progression of NSCLC by downregulating $S L C 34 A 2$ via activating $\mathrm{Wnt} / \beta$-catenin signaling pathway. With more understanding its function,
miR-410 may be used as a potential therapeutic target for NSCLC.

\section{MATERIALS AND METHODS}

\section{MiRNA target prediction by bioinformatics methods}

The miRNA targets predicted by publicly available algorithms were obtained from miRanda (http://www. microrna.org/microrna/home.do) and TargetScan (http:// www.targetscan.org). Putative target genes predicted by both algorithms were accepted.

\section{Cell culture and animals}

HBE, A549, H1299 and 293 cell lines were from American Type Culture Collection (USA). 95D cell lines were purchased from Shanghai Institute of Cell Bank (Shanghai, China). The A549, 95D and H1299 cell lines were cultured in RPMI 1640 (Invitrogen, Carslabd/CA, USA), and HBE/HEK293 cell lines were cultured in dulbecco's modified eagle medium (DMEM) (Invitrogen, Carslabd/CA, USA) supplemented with 10\% fetal bovine serum (Invitrogen, Carslabd/CA, USA) at $37{ }^{\circ} \mathrm{C}$ in $5 \%$ $\mathrm{CO}_{2}$. Female athymic BALB/c nude mice, 3-4 weeks old, obtained from HFK Bioscience (Beijing, China), were maintained at the Animal Core Facility at West China Hospital, Sichuan University under specific pathogen-free (SPF) condition. All studies on mice were conducted in accordance with the National Institutes of Health 'Guide for the Care and Use of Laboratory Animals'.

\section{Lung tumor patient samples}

NSCLC tumor and normal adjacent NT tissue specimens were obtained from 75 patients from Department of Thoracic Surgery, West China Hospital, Sichuan University. This study was performed with the approval of the Medical Ethical Committee of West China Hospital, Sichuan University. A summary of the patients tumor sample characteristics were shown in Table 1.

\section{RNA extraction and quantitative real-time PCR}

Total RNA of NSCLC cell lines and patient tissues were isolated with TRIzol (Invitrogen, Carslabd/CA, USA) according the manufacturer's instructions. cDNAs were generated using PrimeScript ${ }^{\mathrm{TM}}$ RT-PCR Kit (Takara Biotech (Dalian) Co., Ltd, Dalian, China) . Primers for qRT-PCR were as follows: SLC34A2 (NM_006424): Forward, 5'- GAG AAC ATC GCC AAA TGC-3'; 
Reverse, 5'- GCA ACC ACA GAG GAC CAG -3'. $\beta$-actin: Forward, 5'-CTT AGT TGC GTT ACA CCC TTT CTTG-3'; Reverse, 5'-CTT AGT TGC GTT ACA CCC TTT CTTG-3'. MiR-410 (MIMAT0002171) stem-loop primers and U6 primers were commercially synthesized (RiboBio Co., Ltd, Guangzhou, China). QRT-PCR was performed using a SYBR Green Real-time PCR Master Mix Kit protocol (Bio-Rad, Hercules/ CA, USA) on CFX96 Real-Time System (Bio-Rad, Hercules/CA, USA). $\beta$-actin and U6 were used as internal controls for SLC34A2 and $\mathrm{miR}-410$ respectively. Relative quantification of miR410 or SLC34A2 expression was calculated using the $2^{-\Delta \Delta C t}$ method. All reactions were done in triplicate.

\section{Construction of reporter plasmids and luciferase reporter assay}

Dual-luciferase reporter system (Promega (Beijing) Biotech Co., Ltd, Beijing, China) was used to analysis whether miR-410 would directly target the 3'UTR of SLC34A2. The 3'UTR sequence of the SLC34A2 was amplified by PCR using the flowing primers: Forward, 5'-GCG AGC TCG CTG CGC TCC AGC CTT ATCT3'; Reverse, 5'-GCT CTA GAG CAA GCC TGC CTC ATT TCC A-3', and the 200 bp amplicon was cloned into pMIR vector (Promega (Beijing) Biotech Co., Ltd, Beijing, China) to produce wild-type reporter (PmirGLOSLC34A2 3'UTR-F). The mutant reporter (PmirGLOSLC34A2 3'UTR-R) construct was generated by fusing the reversed amplicon (amplified by using the flowing primers: Forward, 5'-GCG CTA GCG CCC ACA GAT GGG CTT TGAT -3'; Reverse, 5'-GCT CTA GAG CCT TGC TGC ACG GCT ACAC-3') into pMIR vector. For luciferase reporter assay, HEK-293 cells cultured in 96-well plate were cotransfected with PmirGLO-SLC34A2 3'UTR-F or PmirGLO-SLC34A2 3'UTR-R, and miR-410 mimics or negative control (NC), following the manufacturer's protocol of Lipo2000 (Invitrogen, Carslabd/ CA, USA). Luciferase activity was detected $24 \mathrm{~h}$ post-transfection according to dual-luciferase reporter assay system (Promega (Beijing) Biotech Co., Ltd, Beijing, China). The Renilla luciferase signals were normalized to the internal firefly luciferase transfection control. Transfections were done at least thrice in independent experiments.

\section{Western blotting}

Western Blotting was used to detect the influence of miR-410 and SLC34A2 on key proteins of $\mathrm{Wnt} / \beta$-catenin signaling pathway. A549 or 95D cells were transfected with miR-410 mimics/NC or miR-410 inhibitors/NC, or transfected with $\mathrm{p} 3.1-S L C 34 A 2 / \mathrm{p} 3.1$ or siRNA-SLC34A2/ siRNA-NC or cotransfected with siRNA-SLC34A2 and miR-410 inhibitors/ $\mathrm{NC}$ according to the instructions of Lipo2000. The total membrane proteins were extracted
$24 \mathrm{hr}$ post-transfection according to the manufacturer's instructions (Promega (Beijing) Biotech Co., Ltd, Beijing, China). Total cell protein was extracted using RIPA lysis buffer containing protease inhibitor cocktail at 1:100 dilution. Protein concentrations were measured using a BCA protein assay kit. The protein level was quantified by Western blotting analysis of $50 \mu \mathrm{g}$ of cell extracts or tissue extracts. The following primary antibodies were used: anti- $\beta$-catenin (Cell Signaling Technology, Danvers, MA, USA, 1:1000), anti-DVL2 (Cell Signaling Technology, Danvers, MA, USA, 1:1000), anti-Gsk3 $\beta$ (Cell Signaling Technology, Danvers, MA, USA, 1:1000), anti- $\beta$-actin (Cell Signaling Technology, Danvers, MA, USA, 1:1000), anti-SLC34A2 (Santa Cruz, CA, USA, 1:500), $\beta$-actin was used as an internal control.

\section{Cell proliferation assay}

In vitro proliferation assay was used to detect the influence of miR-410 on the growth of A549 and 95D cell lines and also determine whether SLC34A2 were engaged in miR-410 inhibitor-mediated growth suppression. A549 or 95D cells cultured in 96-well plates (4000/ well) were transfected with miR-410 inhibitors/NC or miR-410 mimics/NC, or cotransfected with miR-410 inhibitors/NC and siRNA-SLC34A2/NC. Cell viability was evaluated with 3-(4, 5-dimethylthiazol-2-yl)-2, 5-diphenyltetrazolium bromide (MTT; Sigma, St. Louis, MO, USA) as described previously [26].

\section{Flow-cytometric analysis of apoptosis}

In order to detect the influence of miR-410 on apoptosis of A549 and 95D cells. Cells cultured in 6-well plates were transfected with miR-410 inhibitors/ $\mathrm{NC}$ or miR-410 mimics/NC. $24 \mathrm{~h}$ after transfection, cells $\left(2 \times 10^{5}\right.$ /well) were seeded into fresh six-well plates. FITCAnnexin V and Propidium iodide (PI) was added 24h later and apoptotic cells were identified with a flow cytometer (BD Biosciences, San Diego, CA, USA) according to manufacturer's protocol.

\section{In vitro invasion and migration assay}

In vitro Transwell and Millicell assay were used for detecting the influence of miR-410 on the invasion and migration of A549 and 95D cell lines by targeting SLC34A2. A549 or 95D cells cultured in 6-well plates were transfected with miR-410 inhibitors/NC or miR-410 mimics/NC, or cotransfected with miR-410 inhibitors/ $\mathrm{NC}$ and siRNA-SLC $34 A 2$ respectively. For the migration assays, cell dilutions in serum-free media were placed respectively into the upper chamber of an insert (8$\mu \mathrm{m}$ pore size, Millipore, Billerica, MA, USA). For the 
invasion assays, A549 or 95D cells cultured in 6-well plates were transfected with miR-410 inhibitors/NC or miR-410 mimics/NC, or cotransfected with miR-410 inhibitors $/ \mathrm{NC}$ and siRNA-SLC34A2 respectively. 24h after transfection, cells were harvested and cell dilutions were placed into the upper chamber of an insert coated with Matrigel (BD Biosciences, San Diego, CA, USA). Media containing $10 \%$ FBS were added to the lower chamber. After 24 hours of incubation, the cells remaining on the upper membrane were removed with cotton wool, whereas the migrated or invaded cells were stained with methanol and $0.1 \%$ crystal violet, then were imaged and counted.

\section{Establishment of miR-410 knockdown stable cell line}

MiR-410 inhibitor recombinant lentivirus solution (HmiR-AN0244-AM03, Guangzhou Fulengen Co., Ltd, Guangzhou, China) and control lentivirus solution (CmiR-AN0001-AM03, Guangzhou Fulengen Co., Ltd, Guangzhou, China) were purchased from company. For generation of miR-410 knockdown stable cell line (INHLV) and negative control (INH-NC-LV), A549 cells were infected with lentivirus particles containing miR-410 inhibitor vector (HmiR-AN0244-AM03, Guangzhou Fulengen Co., Ltd, Guangzhou, China) or scrambled control clone for pEZX-AM03 (CmiR-AN0001-AM03, Guangzhou Fulengen Co., Ltd, Guangzhou, China) with Polybrene ( $5 \mu \mathrm{g} / \mathrm{ml}$; Sigma, St.Louis, MO, USA). Medium containing lentiviral particles was replaced with fresh medium $24 \mathrm{~h}$ post-infection and then incubated for $72 \mathrm{~h}$. Stable cells were selected after infection using hygromycin $(200 \mu \mathrm{g} / \mathrm{ml}$; Roche, USA) by 4 weeks. Medium containing hygromycin was replaced every 3 days. The stable cell lines were further identified by detection of miR-410 expression by qRT-PCR.

\section{Animal study}

In order to detect the effects of miR-410 on migration and invasion of non-small lung cancer cells in vivo, miR-410 knockdown stable cells INH-LV and negative control INH-NC-LV cells were used to establish lung metastasis mouse model respectively according to the described method $[28,29]$. Briefly, cells were injected via tail vein into 3 week-old BALB/c nude mice $\left(3 \times 10^{6}\right.$ cells per mouse, eight mice in each group). About five weeks later, eight mice were anesthetized, lungs of five mice were injected intratracheally with India ink and fixed by AAF solution ( $85 \%$ ethanol, $10 \%$ acetic acid, $5 \%$ formalin) to count the number of metastatic tumor nodules (white dots) on lung surfaces. The sizes of the metastatic nodules were observed and the relative metastatic inhibition ratio was calculated in terms of the tumor nodules in INH-LV and
INH-NC-LV group relative to that of blank control. Then, lungs of three mice were excised and fixed in $4 \%$ buffered paraformaldehyde for further pathological analysis. Lung sections were stained with hematoxylin and eosin (H\&E) to visualize the metastatic tumor nodules in lungs.

\section{Methylation-specific PCR (MSP) and bisulfite sequencing}

In order to determine whether miR-410 abnormal expression was regulated by $\mathrm{CpG}$ methylation, we checked the methylation status of $\mathrm{CpG}$ islands 48 upstream of miR410 in NSCLC cell lines. Genomic DNA was extracted using Universal Genomic DNA Extraction Kit Ver.3.0 (Takara Biotech (Dalian) Co., Ltd, Dalian, China). Sodium bisulfite modification was applied to the genomic DNA in line with the CpGenome ${ }^{\mathrm{TM}}$ Fast DNA Modification Kit (Chemicon, Billerica, MA, USA).

Methylation-specific PCR and bisulfite sequencing were used to detect the methylation status of $\mathrm{CpG}$ islands 48 of miR-410. Firstly, genomic DNA after bisulfite modification was amplified according to the instructions of EpiTect Whole Bisulfitome Kit (Qiagen, Valencia, CA, USA). Then $2 \mu \mathrm{L}$ of the amplified products were used as templates for methylation specific PCR (MSP) and bisulfite sequencing PCR (BSP). MethPrimer (http:// www.urogene.org/ methprimer/index.html) software were used to design MSP and BSP primers and the MSP primer sequences were as follows: Forward-methylated: 5'-GTT TTT TTG AGG GTA GGA GTA GGA C-3'; Reversemethylated: 5'-AAA TAC CAT CGA CTC AAA AAC GTA-3'; Forward-unmethylated: 5'-GTT TTT TTG AGG GTA GGA GTA GGA T-3'; Reverse-unmethylated: 5'AAA TAC CAT CAA CTC AAA AAC ATA-3'. Primer sequences for BSP were as follows: Forward, 5'-AGT TTT TTT GAG GGT AGG AGT AGG A-3'; Reverse, 5'-CTT CTC AAA TAC CCA AAA TAC CAT C-3'. BSP products from gel recycling were cloned into pGM-T vector according to the manufacturer's instructions (Tiangen Biotech Co., Ltd, Beijing, China) and transformed into DH5 $\alpha$ competent cells. At least five positive clones in each cell line or control were picked for sequencing.

To further detect the effects of methylation or acetylation on miR-410 expression, methylation inhibitor DAC (5'-aza-2'-deoxycytidine; Sigma, St.Louis, MO, USA) and histone deacetylase inhibitor TSA (trichostatin A; Sigma, St.Louis, MO, USA) were used to treat cells. 95D and A549 cells $\left(3 \times 10^{5} /\right.$ well $)$ seeded in 6 -well plates were treated with DAC ( 1 or $5 \mu \mathrm{M}$, or TSA $(0.05$ or 0.2 $\mu \mathrm{M})$ for $24 \mathrm{~h}$ respectively. Cells were harvested after treatment and total mRNA was extracted for detecting the expression of miR-410 by qRT-PCR. 


\section{Statistical analysis}

The data were presented as mean $\pm \mathrm{SD}$ of at least three independent experiments. The significance of difference between the experimental groups and control was assessed by one-way ANOVA analysis in SPSS 19.0 software. A value of $p<0.05$ was considered as statistically significant.

\section{Abbreviations}

NSCLC: non-small cell lung cancer; QRT-PCR: quantitative real-time PCR; 3'UTR: 3'untranslated region; miRNA: microRNA; mRNA: messenger RNA.

\section{ACKNOWLEDGMENTS}

This study was partly supported by The National 973 Plan Project (2010CB529906) and the National Science and Technology Major Projects of New Drugs (2012ZX09103301-009).

\section{CONFLICTS OF INTEREST} exists.

The authors have declared that no competing interest

\section{REFERENCES}

1. Siegel RL, Miller KD and Jemal A. Cancer statistics, 2015. Ca-cancer J. Clin. 2015; 65: 5-29.

2. Wagner CA, Hernando N, Forster IC, Biber J. The SLC34 family of sodium-dependent phosphate transporters. Pflugers Arch-Eur J Physiol. 2014; 466: 139-153.

3. Cerri MF, Rezende LC, Paes FM. The cotransporter NaPi-IIb: Characteristics, regulation and its role in carcinogenesis. Applied Cancer Research. 2010; 30: $197-$ 203.

4. Virkki LV, Biber J, Murer H, Forster IC. Phosphate transporters: a tale of two solute carrier families. Am J Physiol Renal Physiol. 2007; 293: 643-654.

5. Forster IC, Hernando N, Biber J, Murer H. Proximal tubular handling of phosphate: A molecular perspective. Kidney Int. 2006; 70: 1548-1559.

6. Xu H, Bai L, Collins JF, Ghishan FK. Molecular cloning, function and characterization, tissue distribution, and chromosomal localization of a human, small intestinal sodium-phosphate (Na+-Pi) transporter (SLC34A2). Genomics. 1999; 62: 281-284.

7. Field JA, Zhang L, Brun KA, Brooks DP, Edwards RM. Cloning and functional characterization of a sodiumdependent phosphate transporter expressed in human lung and small intestine. Biochem Biophys Res Commun. 1999;
258: 578-582.

8. Takeda E, Yamamoto H, Nashiki K, Sato T, Arai H, Taketani Y. Inorganic phosphate homeostasis and the role of dietary phosphorus. J Cell Mol Med. 2004; 8:191-200.

9. Hashimoto M, Wang DY, Kamo T, Zhu Y, Tsujiuchi T, Konishi Y, Tanaka M, Sugimura H. Isolation and localization of type $\mathrm{IIb} \mathrm{Na} / \mathrm{Pi}$ cotransporter in the developing rat lung. The American Journal of Pathology. 2000; 157: 21-27.

10. Traebert M, Hattenhauer O, Murer H, Kaissling B, Biber J. Expression of type II Na-Pi cotransporter in alveolar type II cells. American Journal of Physiology-Lung Cellular and Molecular Physiology. 1999; 277: 868-873.

11. Desai TJ, Brownfield DG, Krasnow MA. Alveolar progenitor and stem cells in lung development, renewal and cancer. Nature. 2014; 507: 190-4.

12. Jackson EL, Willis N, Mercer K, Bronson RT, Crowley D, Montoya R, Jacks T, Tuveson DA. Analysis of lung tumor initiation and progression using conditional expression of oncogenic K-ras. Genes and development. 2001; 15: 3243.

13. Kim CF, Jackson EL, Woolfenden AE, Lawrence S, Babar I, Vogel S, Crowley D, Bronson RT, Jacks T. Identification of bronchioalveolar stem cells in normal lung and lung cancer. Cell. 2005; 121: 823-835.

14. Barkauskas CE, Cronce MJ, Rackley CR, Bowie EJ, Keene DR, Stripp BR, Randell SH, Noble PW, Hogan BL. Type 2 alveolar cells are stem cells in adult lung. J Clin Invest. 2013; 123: 3025-36

15. Kopantzev EP, Monastyrskaya GS, Vinogradova TV, Zinovyeva MV, Kostina MB, Filyukova OB, Tonevitsky AG, Sukhikh GT, Sverdlov ED. Differences in gene expression levels between early and later stages of human lung development are opposite to those between normal lung tissue and non-small lung cell carcinoma. Lung Cancer. 2008; 62: 23-34.

16. Yang W, Wang Y, Pu Q, Ye S, Ma Q, Ren J, Zhong G, Liu L, Zhu W. Elevated expression of SLC34A2 inhibits the viability and invasion of A549 cells. Mol Med Rep. 2014; 10: 1205-14.

17. Wang Y, Yang W, Pu Q, Yang Y, Ye S, Ma Q, Ren J, Cao Z, Zhong G, Zhang X, Liu L, Zhu W. The effects and mechanisms of SLC34A2 in tumorigenesis and progression of human non-small cell lung cancer. J Biomed Sci. 2015; 22: 52 .

18. Alvarez-Garcia I, Miska EA. MicroRNA functions in animal development and human disease. Development. 2005; 132: 4653-4662.

19. Friedman LM, Dror AA, Mor E, Tenne T, Toren G, Satoh T, Biesemeier DJ, Shomron N, Fekete DM, Hornstein E, Avraham KB. An overview of microRNAs. Adv Drug Deliv Rev. 2015; 87: 3-14.

20. Barger JF, Nana-Sinkam SP. MicroRNA as tools and therapeutics in lung cancer. Respir Med. 2015; 109(7): 803812. 
21. Mishra S, Lin CL, Huang TH, Bouamar H, Sun LZ. MicroRNA-21 inhibits p57Kip2 expression in prostate cancer. Mol Cancer. 2014; 13: 212.

22. Arabi L, Gsponer JR, Smida J, Nathrath M, Perrina V, Jundt G, Ruiz C, Quagliata L, Baumhoer D. Upregulation of the miR-17-92 cluster and its two paraloga in osteosarcomareasons and consequences. Genes Cancer. 2014; 5: 56-63. doi:10.18632/genesandcancer.6.

23. Yan X, Chen X, Liang H, Deng T, Chen W, Zhang S, Liu M, Gao X, Liu Y, Zhao C, Wang X, Wang N, Li J, et al. MiR-143 and miR-145 synergistically regulate ERBB3 to suppress cell proliferation and invasion in breast cancer. Mol Cancer. 2014; 13: 220.

24. Achari C, Winslow S, Ceder Y, Larsson C. Expression of miR-34c induces G2/M cell cycle arrest in breast cancer cells. BMC Cancer. 2014; 14: 538.

25. Minn YK, Lee da H, Hyung WJ, Kim JE, Choi J, Yang SH, Song H, Lim BJ, Kim SH. MicroRNA-200 family members and ZEB2 are associated with brain metastasis in gastric adenocarcinoma. Int J Oncol. 2014; 45:2403-10.

26. Li J, Huang H, Sun L, Yang M, Pan C, Chen W, Wu D, Lin Z, Zeng C, Yao Y, Zhang P, Song E. MiR-21 indicates poor prognosis in tongue squamous cell carcinomas as an apoptosis inhibitor. Clin Cancer Res. 2009; 15: 3998-4008.

27. Ito I, Ji L, Tanaka F, Saito YJ, Gopalan B, Branch CD, Xu K, Atkinson EN, Bekele BN, Stephens LC, Minna JD, Roth JA, and Ramesh R. Liposomal vector mediated delivery of the $3 p$ FUS1 gene demonstrates potent antitumor activity against human lung cancer in vivo. Cancer Gene Therapy. 2004; 11: 733-739.

28. Ou W, Ye S, Yang W, Wang Y, Ma Q, Yu C, Shi H, Yuan Z, Zhong G, Ren J, Zhu W and Wei Y. Enhanced antitumor effect of cisplatin in human NSCLC cells by tumor suppressor LKB1. Cancer Gene Therapy. 2012; 19: 489 - 498 .

29. Chien WW, Domenech C, Catallo R, Kaddar T, Magaud JP, Salles G, Ffrench M. Cyclin-dependent kinase 1 expression is inhibited by p16(ink4a) at the post-transcriptional level through the microrna pathway. Oncogene. 2011; 30:18801891.

30. Chen L1, Zhang J, Feng Y, Li R, Sun X, Du W, Piao X, Wang H, Yang D, Sun Y, Li X, Jiang T, Kang C, et al. MiR-410 regulates MET to influence the proliferation and invasion of glioma. Int J Biochem Cell Biol. 2012; 44:17111717.

31. Zhao D, Jia P, Wang W, Zhang G. VEGF-mediated suppression of cell proliferation and invasion by miR-410 in osteosarcoma. Mol Cell Biochem. 2015; 400:87-95.

32. Shen J, Niu W, Zhou M, Zhang H, Ma J, Wang L, Zhang H. MicroRNA-410 suppresses migration and invasion by targeting MDM2 in gastric cancer. PLoS One. 2014; 9(8): e104510.

33. Wang Y, Fu J, Jiang M, Zhang X, Cheng L, Xu X, Fan Z, Zhang J, Ye Q, Song H. MiR-410 is overexpressed in liver and colorectal tumors and enhances tumor cell growth by silencing FHL1 via a direct/ indirect mechanism. PLoS One. 2014; 9: e108708.

34. Yin BW, Kiyamova R, Chua R, Caballero OL, Gout I, Gryshkova V, Bhaskaran N, Souchelnytskyi S, Hellman U, Filonenko V, Jungbluth AA, Odunsi K, Lloyd KO, et al. Monoclonal antibody MX35 detects the membrane transporter NaPi2b (SLC34A2) in human carcinomas. Cancer Immun. 2008; 8: 3.

35. Kawazoe Y, Katoh S, Onodera Y, Kohgo T, Shindoh M and Shiba T. Activation of the FGF signaling pathway and subsequent induction of mesenchymal stem cell differentiation by inorganic polyphosphate. Int J Biol Sci. 2008; 4: 37-47.

36. Mashima H, Zhang YQ, Tajima T, Takeda J and Kojima I. $\mathrm{Na}-\mathrm{Pi}$ cotransporter expressed during the differentiation of pancreatic AR42J cells. Diabetes. 2001; 50: S39.

37. Kahn M. Can we safely target the WNT pathway? Nat Rev Drug Discov. 2014; 13: 513-532.

38. Snyder CM, Rice AL, Estrella NL, Held A, Kandarian SC, Naya FJ. MEF2A regulates the Gt12-Dio3 microRNA mega-cluster to modulate WNT signaling in skeletal muscle regeneration. Development. 2013; 140: 31-42.

39. Chuang JC, Jones PA. Epigenetics and microRNAs. Pediatr Res. 2007; 61: 24-29.

40. Egger G, Liang G, Aparicio A, Jones PA. Epigenetics in human disease and prospects for epigenetic therapy. Nature. 2004; 429: 457-463. 